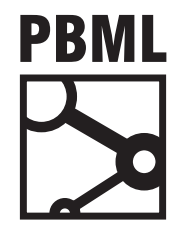

The Prague Bulletin of Mathematical Linguistics

NUMBER 105 APRIL $2016 \quad 143-193$

\title{
Universal Annotation of Slavic Verb Forms
}

\author{
Daniel Zeman
}

Charles University in Prague, Faculty of Mathematics and Physics, Institute of Formal and Applied Linguistics

\begin{abstract}
This article proposes application of a subset of the Universal Dependencies (UD) standard to the group of Slavic languages. The subset in question comprises morphosyntactic features of various verb forms. We systematically document the inventory of features observable with Slavic verbs, giving numerous examples from 10 languages. We demonstrate that terminology in literature may differ, yet the substance remains the same. Our goal is practical. We definitely do not intend to overturn the many decades of research in Slavic comparative linguistics. Instead, we want to put the properties of Slavic verbs in the context of UD, and to propose a unified (Slavic-wide) application of UD features and values to them. We believe that our proposal is a compromise that could be accepted by corpus linguists working on all Slavic languages.
\end{abstract}

\section{Introduction and related work}

Universal Dependencies (Nivre et al., 2016) ${ }^{1}$ is a project that seeks to design crosslinguistically consistent treebank annotation for as many languages as possible. Besides dependency relations, UD also defines universally applicable tags for parts of speech (universal POS tags) and common morphosyntactic features (universal features). The features are taken from a previous project called Interset (Zeman, 2008).

Being suitable for a variety of unrelated languages means that the core concepts of UD must be sufficiently general; at the same time, their definitions must be descriptive enough to signal that two phenomena in two different languages are (or are not) the same thing, despite conflicts in traditional terminologies.

There is always the danger that researchers working on different languages will apply the UD concepts differently. As UD gains on popularity and new datasets are

\footnotetext{
${ }^{1}$ http://universaldependencies.org/
} 
converted to its annotation scheme, enforcing consistency is an increasingly important issue. It seems natural to start with looking at closely related languages and first make sure that they annotate the same things same way; then widen the view to larger language groups and so on.

The first work on Slavic-specific issues in UD was Zeman (2015). The present article focuses on part-of-speech tags and features of individual words, not on interword dependency relations. Some verb forms are analytical (periphrastic), made of two or more individual words. We occasionally use the periphrastic constructions for illustrative purposes but bear in mind that tags and features must be assigned to individual words only. Also note that UD postulates the concept of syntactic word, something that is not necessarily identical to the space-delimited orthographic word. An orthographic word may be understood as a fusion of two or more syntactically autonomous units; the annotation treats each of them separately.

Some work has been published that pre-dates UD and is related to our current effort. Besides Interset (Zeman, 2015), the outcomes of the MULTEXT-East project are highly relevant (Erjavec, 2012). Quite a few Slavic languages have morpho-syntactic tagsets stemming from MULTEXT-East. These tagsets are similar to each other and they were indeed intended to encode the same phenomena identically across languages. Unfortunatelly they have not always reached this goal. Traditional views and legacy resources sometimes outweighed the desire for uniformity. UD faces the same danger and we should strive hard to avoid it.

In the following sections we discuss UD tags and features applicable to Slavic verbs (as well as some words on the border between verbs and other parts of speech). We give numerous examples and inflection tables together with the proposed annotation. 2 We list the native names of the verb forms in the beginning of each section.

We use ISO 639 language codes when refering to individual languages: [be] Belarusian, [bg] Bulgarian, [cs] Czech, [cu] Old Church Slavonic, [dsb] Lower Sorbian, [hr] Croatian, [hsb] Upper Sorbian, [mk] Macedonian, [pl] Polish, [ru] Russian, [sk] Slovak, [sl] Slovenian, [sr] Serbian, [uk] Ukrainian.

Six Slavic languages ([bg], [cs], [cu], [hr], [pl] and [sl]) already have datasets in the current release of UD (1.2) and other languages are expected to get covered in the near future. We briefly summarize the approaches taken in the current data in Section 18 .

\section{Universal Features}

The following universal features are discussed in the article. See the on-line documentation of UD (http: //universaldependencies.org/) for their detailed description with examples. Here we provide just a list for quick reference:

\footnotetext{
${ }^{2}$ The tables were compiled using on-line resources such as Wictionary, verb conjugators and language courses, as well as printed grammars and dictionaries. We do not cite these sources individually due to space considerations.
} 
- Aspect: Imp (imperfective), Perf (perfective)

- VerbForm: Fin (finite verb), Inf (infinitive), Sup (supine), Part (participle), Trans (transgressive)

- Mood: Ind (indicative), Imp (imperative), Cnd (conditional)

- Tense: Past (past), Imp (imperfect), Pres (present), Fut (future)

- Voice: Act (active), Pass (passive)

- Number: Sing (singular), Dual (dual), Plur (plural)

- Person: 1, 2, 3

- Gender: Masc (masculine), Fem (feminine), Neut (neuter)

- Animacy: Anim (animate/human), Nhum (animate nonhuman), Inan (inanimate)

- Case: Nom (nominative), Gen (genitive), Dat (dative), Acc (accusative), Voc (vocative), Loc (locative), Ins (instrumental)

- Definite: Ind (indefinite), Def (definite)

- Negative: Pos (affirmative), Neg (negative)

\section{Universal Part of Speech Tag and Lemma}

We discuss various finite and non-finite forms of verbs in Slavic languages. We include some forms on the border of verbs and other parts of speech because we want to define the borderline between parts of speech uniformly for all Slavic languages.

We propose a simple (but approximate!) rule of thumb: if it inflects for Case, it is not a VERB. It is either an ADJ, or a NOUN. We treat such forms as adjectives or nouns derived from verbs. Nevertheless, they may have some features such as VerbForm and Tense that are normally used with verbs and that do not occur with other adjectives and nouns.

Verbal nouns have the neuter gender and they are rarely seen in plural.

Participles may, depending on language, have short and long forms. The long forms almost always inflect for Case and can be used attributively (as modifiers of nouns). We propose to classify them as adjectives. The short forms of some participle types receive the VERB tag: it signals that their inflection is limited $\underline{3}$ and their usage is prevailingly predicative. In south Slavic languages even some short participles inflect for Case $\underline{4}$ and get the ADJ tag; the short vs. long forms differ in the feature of Definite(ness) there.

Only a few Slavic verbs may function as auxiliaries and be tagged AUX. All of them may also be tagged VERB in other contexts. The main auxiliary verb is to be (být, bývat, byt', być, бymu, бbtmb, biti...) It may be used to form the future tense, past tense, conditional and passive. Serbo-Croatian languages use a different auxiliary verb, $h t j e t i$

\footnotetext{
${ }^{3} \mathrm{~A}$ rare example of short form inflection in Czech is the feminine accusative, e.g. udèlánu.

${ }^{4}$ Actually only a few forms-masculine singular nominative and masculine inanimate singular accusative-distinguish "long" vs. "short" forms in [sl] and [hr]. In the other cases there is just one form and it does not make much sense to classify it as either long or short.
} 
"will", to form the future tense. We do not see any benefit in granting the auxiliary status to verbs that are not needed in periphrastic verb forms; in particular, modal verbs are tagged VERB, although UD for Germanic languages treats them as auxiliaries. In accord with the UD guidelines, the verb to be is tagged VERB if it functions as copula.

All words tagged VERB or AUX must have a non-empty value of the feature VerbForm.

The POS tag also determines what word form will be used as the lemma. For VERB and AUX, the lemma is the infinitive (Section 5 ),, except for [bg] and [mk]: these languages do not have infinitives, and present indicative forms are used as lemmas there. However, if the word is tagged ADJ, the masculine singular nominative form of the adjective serves as the lemma. The annotation does not show the infinitive of the base verb (except for an optional reference in the MISC column). Similarly, the lemma of a verbal NOUN is its singular nominative form.

\section{Aspect}

Slavic languages distinguish two aspects: imperfective (Aspect=Imp) and perfective (Aspect=Perf). The feature is considered lexical, that is, all forms of one lemma (usually) belong to the same aspect. A few verbs (many of them loanwords from nonSlavic languages) work with both aspects. We omit the Aspect feature at these verbs. Most Slavic verbs are part of inflected aspect pairs where one verb is imperfective and the other is perfective. They have different lemmas and the morphological processes that create one from the other are considered derivational. Examples (Imp - Perf): [cs] dělat - udělat "to do", sedět - sednout "to sit", kupovat - koupit "to buy", brát - vzit "to take". Although the meaning of the two verbs is similar, in perfective verbs the action is completed and in imperfective verbs it is ongoing.

The equivalents of the verb to be are imperfective.

\section{Infinitive and Supine}

[cs] infinitiv, neurčitek; [sk] infinitív, neurčitok; [hsb] infinitiw; [pl] bezokolicznik; [uk] інфінітив; [ru] инфинитив; [sl] nedoločnik (Inf), namenilnik (Sup); [hr] infinitiv. Таbles 1 and 2.

Most Slavic languages have a distinct infinitive form, which is used as argument of modal and other verbs (control, purpose), and sometimes in construction of the periphrastic future tense. The infinitive is also used as the citation form of verbs. It does not exist in Macedonian and Bulgarian.

Czech has two forms of infinitive, e.g. dělat and dělati "to do". The longer form with the final $-i$ is considered archaic, otherwise they are grammatically equivalent.

\footnotetext{
${ }^{5}$ We do not prescribe whether inherently reflexive verbs such as [cs] smát se "to laugh" should or should not have the reflexive pronoun incorporated in their lemma.
} 


\begin{tabular}{|c|c|c|c|c|c|}
\hline en & to be & can & to go & to do & to accept \\
\hline CS & být, býti & moct, moci & jít, jíti & dělat, dělati & akceptovat, akceptovati \\
\hline sk & $b y t^{\prime}$ & môct' & ist' & robit' & akceptovat' \\
\hline hsb & być & móc & hić & dźěłać & akceptować \\
\hline pl & być & móc & $i S^{\prime} c^{\prime}$ & robić & akceptować \\
\hline uk & $\begin{array}{l}\text { бymu } \\
\text { buty }\end{array}$ & $\begin{array}{l}\text { могmu } \\
\text { mohty }\end{array}$ & $\begin{array}{l}\breve{u} m u \\
j t y\end{array}$ & $\begin{array}{l}\text { poбumu } \\
\text { robyty }\end{array}$ & $\begin{array}{l}\text { акцептувати } \\
\text { akceptuvaty }\end{array}$ \\
\hline $\mathrm{ru}$ & $\begin{array}{l}\text { бbrmb } \\
\text { byt' }\end{array}$ & $\begin{array}{l}\text { мочь } \\
\text { moс́ }\end{array}$ & $\begin{array}{l}\text { uдmu } \\
\text { idti }\end{array}$ & $\begin{array}{l}\text { делаmь } \\
\text { delat' }\end{array}$ & $\begin{array}{l}\text { акцептовать } \\
\text { akceptovat' }\end{array}$ \\
\hline sl & biti & moči & $i t i$ & delati & akceptirati \\
\hline $\mathrm{hr}$ & biti & moći & $i c ́ i$ & delati, delat & akceptirati, akceptirat \\
\hline $\mathrm{cu}$ & $\begin{array}{l}\text { Бытн } \\
\text { byti }\end{array}$ & $\begin{array}{l}\text { моџ̆н } \\
\text { mošti }\end{array}$ & $\begin{array}{l}\mathrm{HTH} \\
\text { iti }\end{array}$ & 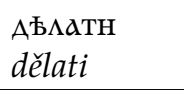 & \\
\hline
\end{tabular}

Table 1. VerbForm=Inf

\begin{tabular}{|c|c|c|c|c|c|}
\hline en & to be & can & to go & to do & to accept \\
\hline sl & bit & & it & delat & akceptirat \\
\hline $\mathrm{cu}$ & $\begin{array}{l}\text { БЫтъ } \\
\text { bytъ }\end{array}$ & & $\begin{array}{l}\text { НTъ } \\
\text { itъ }\end{array}$ & $\begin{array}{l}\text { АБиать } \\
\text { dělatъ }\end{array}$ & \\
\hline
\end{tabular}

Table 2. VerbForm=Sup

In contrast, Slovenian uses only the longer form (delati) as infinitive, while the shorter form is called supine and is used after motion verbs (meaning "to go somewhere to do something").. In Croatian both are considered infinitive but the short form is only used in future tense if the infinitive precedes the auxiliary verb: Učit ću hrvatski. "I will learn Croatian." but Hoću učiti hrvatski.

Infinitive and supine verbs lack most other verbal features, they only have nonempty values of Aspect, VerbForm and in some languages also of Negative.

\section{Present and Future Indicative}

[cs] přitomný čas (prézens), budoucí čas (futurum); [sk] prítomný čas, budúci čas; [hsb] prezens, futur; [pl] czas teraźniejszy, czas przyszly; [uk] mеперішній иас, майбутній иас;

\footnotetext{
${ }^{6}$ The supine is an old form, attested in Old Church Slavonic. Besides Slovenian, it has also survived in Lower Sorbian.
} 


\begin{tabular}{|c|c|c|c|c|c|c|c|c|c|}
\hline Number & \multicolumn{3}{|c|}{ Sing } & \multicolumn{3}{|c|}{ Dual } & \multicolumn{3}{|c|}{ Plur } \\
\hline Person & 1 & 2 & 3 & 1 & 2 & 3 & 1 & 2 & 3 \\
\hline cS & jsem & $j s i$ & je & & & & jsme & jste & jsou \\
\hline sk & som & $s i$ & je & & & & sme & ste & sú \\
\hline hsb & sym & sy & je & smój & staj & staj & smy & sće & su \\
\hline pl & jestem & jesteś & jest & & & & jesteśmy & jesteście & $s q$ \\
\hline uk & & $\begin{array}{l}\epsilon c u, \epsilon \\
j e s y, j e\end{array}$ & $\begin{array}{l}E \\
j e\end{array}$ & & & & $\begin{array}{l}\epsilon \\
j e\end{array}$ & $\begin{array}{l}\epsilon \\
j e\end{array}$ & $\begin{array}{l}\epsilon \\
j e\end{array}$ \\
\hline $\mathrm{ru}$ & & & $\begin{array}{l}\text { ecmb } \\
\text { est' }\end{array}$ & & & & & & $\begin{array}{l}\text { cymb } \\
\text { sut' }\end{array}$ \\
\hline sl & sem & si & je & sva & sta & sta & smo & ste & so \\
\hline hr & $\begin{array}{l}\text { jesam } \\
\text { sam }\end{array}$ & $\begin{array}{l}j e s i \\
\text { si }\end{array}$ & $\begin{array}{l}\text { jest } \\
\text { je }\end{array}$ & & & & $\begin{array}{l}\text { jesmo } \\
\text { smo }\end{array}$ & $\begin{array}{l}\text { jeste } \\
\text { ste }\end{array}$ & $\begin{array}{l}\text { jesu } \\
\text { su }\end{array}$ \\
\hline bg & $\begin{array}{l}\text { croM } \\
\text { săm }\end{array}$ & $\begin{array}{l}c u \\
s i\end{array}$ & $\begin{array}{l}e \\
e\end{array}$ & & & & $\begin{array}{l}\text { cMe } \\
\text { sme }\end{array}$ & $\begin{array}{l}\text { cme } \\
\text { ste }\end{array}$ & $\begin{array}{l}c a \\
s a\end{array}$ \\
\hline $\mathrm{cu}$ & $\begin{array}{l}\text { Есмъ } \\
\text { jesmь }\end{array}$ & $\begin{array}{l}\mathrm{ECH} \\
j e s i\end{array}$ & $\begin{array}{l}\text { Есть } \\
\text { jestz }\end{array}$ & $\begin{array}{l}\text { Есвь } \\
\text { jesvě }\end{array}$ & $\begin{array}{l}\text { вста } \\
\text { jesta }\end{array}$ & $\begin{array}{l}\text { ЕстЕ } \\
\text { jeste }\end{array}$ & $\begin{array}{l}\text { Есмъ } \\
\text { jesmъ }\end{array}$ & $\begin{array}{l}\text { ЕстЕ } \\
\text { jeste }\end{array}$ & $\begin{array}{l}\text { схтть } \\
\text { sotr }\end{array}$ \\
\hline
\end{tabular}

Table 3. To be, VerbForm=Fin | Mood=Ind | Tense=Pres. Note that in Ukrainian and Russian the original non- $3^{\text {rd }}$ person forms of this verb have become archaic.

[ru] настоящее время, будущее время; [sl] sedanjik, prihodnjik; [hr] sadašnje vrijeme, buduс́ vrijeme; [bg] сегашно време, бъдеще време. Tables 3-15.

Present tense is a simple finite verb form that marks person and number of the subject. Present forms of perfective verbs have a future meaning; however, we prefer morphology (form) to semantics (function) and annotate them Tense=Pres, regardless the aspect and meaning..

Future tense of imperfective verbs is usually formed periphrastically, using infinitive or participle of the content verb, and special forms of the auxiliary verb to be, e.g. [cs] budu dělat "I will do". These special forms are different from the present forms and they are annotated Tense=Fut. The infinitive of the content verb does not have the tense feature.

In Croatian, the periphrastic future is formed using another auxiliary verb, htjeti "will / want". This verb can also be used as a content (non-auxiliary) verb, and its auxiliary forms are not different from its normal present forms. Therefore they will be annotated Tense=Pres.

\footnotetext{
${ }^{7}$ Some tagsets prefer to call these forms non-past verb, cf. Przepiórkowski and Woliński (2003).
} 


\begin{tabular}{|c|c|c|c|c|c|c|c|c|c|}
\hline $\mathrm{Nu}$ & \multicolumn{3}{|c|}{ Sing } & \multicolumn{3}{|c|}{ Dual } & \multicolumn{3}{|c|}{ Plur } \\
\hline $\mathrm{Pe}$ & 1 & 2 & 3 & 1 & 2 & 3 & 1 & 2 & 3 \\
\hline CS & budu & budeš & bude & & & & budeme & budete & budou \\
\hline sk & budem & budeš & bude & & & & budeme & budete & budú \\
\hline hsb & budu & budźeš & budźe & budźemoj & budźetej & budźetej & budźemy & budźeće & budu \\
\hline $\mathrm{pl}$ & będe & będziesz & będzie & & & & będziemy & będziecie & będa \\
\hline uk & $\begin{array}{l}\text { бydy } \\
\text { budu }\end{array}$ & $\begin{array}{l}\text { будеш } \\
\text { budeš }\end{array}$ & $\begin{array}{l}\text { бyдe } \\
\text { bude }\end{array}$ & & & & $\begin{array}{l}\text { будемо } \\
\text { bидето }\end{array}$ & $\begin{array}{l}\text { бydeme } \\
\text { budete }\end{array}$ & $\begin{array}{l}\text { будуmь } \\
\text { budut' }\end{array}$ \\
\hline $\mathrm{ru}$ & $\begin{array}{l}\text { бydy } \\
\text { budu }\end{array}$ & $\begin{array}{l}\text { будешь } \\
\text { budeš' }\end{array}$ & $\begin{array}{l}\text { бydem } \\
\text { budet }\end{array}$ & & & & $\begin{array}{l}\text { будем } \\
\text { budem }\end{array}$ & $\begin{array}{l}\text { бydeme } \\
\text { budete }\end{array}$ & $\begin{array}{l}\text { бydym } \\
\text { budut }\end{array}$ \\
\hline $\mathrm{sl}$ & bom & boš & bo & bova & bosta & bosta & bomo & boste & bodo \\
\hline $\mathrm{cu}$ & $\begin{array}{l}\text { БЖАस } \\
\text { bod }\end{array}$ & $\begin{array}{l}\text { БХАЕШН } \\
b q d e s ̌ i\end{array}$ & $\begin{array}{l}\text { БХАЕТЬ } \\
\text { bodet } 6\end{array}$ & $\begin{array}{l}\text { БХАЕВБ } \\
\text { bodevě }\end{array}$ & $\begin{array}{l}\text { БХАЕта } \\
\text { bodeta }\end{array}$ & $\begin{array}{l}\text { БХАЕТЕ } \\
\text { bodete }\end{array}$ & $\begin{array}{l}\text { БХАЕМъ } \\
\text { bodemъ }\end{array}$ & $\begin{array}{l}\text { БХАЕТЕ } \\
\text { bodete }\end{array}$ & $\begin{array}{l}\text { Бхлхтъ } \\
b o d \varphi t z\end{array}$ \\
\hline
\end{tabular}

Table 4. To be, VerbForm=Fin | Mood=Ind | Tense=Fut.

A handful of Czech, Slovak and Slovenian motion verbs also have simple future forms, created by the prefix p[oóôi]]-: [cs] půjde "he will go", pojede "he will ride", poleti "he will fly" but also pokvete "it will bloom". In these cases the prefix is not derivational because it does not create a new perfective lemma with a full paradigm. Thus we annotate these forms as future so they are distinguished from the present forms. In other languages the situation may be different. Russian noŭmu (pojti) is a full perfective counterpart of the imperfective $u \partial m u$ (idti) and its present forms are annotated Tense=Pres.

Ukrainian is special in that it has regular simple future forms of imperfective verbs (not restricted to motion verbs). The periphrastic future also exists. 


\begin{tabular}{|c|c|c|c|c|c|c|}
\hline Number & \multicolumn{3}{|c|}{ Sing } & \multicolumn{3}{|c|}{ Dual } \\
\hline Person & 1 & 2 & 3 & 1 & 2 & 3 \\
\hline $\mathrm{CS}$ & pi̊jdu & půjdeš & puijde & & & \\
\hline sk & pôjdem & pôjdeš & pôjde & & & \\
\hline hsb & póndu & pónddźeš & póndźe & póndźemoj & póndźetej & póndźetej \\
\hline sl & pojdem & pojdeš & pojde & pojdeva & pojdeta & pojdeta \\
\hline uk & 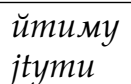 & 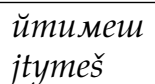 & $\begin{array}{l}\text { йтиме } \\
\text { jtyme }\end{array}$ & & & \\
\hline
\end{tabular}

\begin{tabular}{|c|c|c|c|}
\hline \multirow{2}{*}{$\begin{array}{l}\text { Number } \\
\text { Person }\end{array}$} & \multicolumn{3}{|c|}{ Plur } \\
\hline & 1 & 2 & 3 \\
\hline CS & puijdeme & puijdete & půjdou \\
\hline sk & pôjdeme & pôjdete & pôjdu \\
\hline hsb & póńdźemy & póndźeće & póndu \\
\hline $\mathrm{sl}$ & pojdemo & pojdete & pojdejo \\
\hline uk & $\begin{array}{l}\breve{и т и м е м о ~} \\
\text { jtутето }\end{array}$ & $\begin{array}{l}\text { ümuмeme } \\
\text { jtymete }\end{array}$ & $\begin{array}{l}\breve{u} т и м у т ь \\
\text { jtymut' }\end{array}$ \\
\hline
\end{tabular}

Table 5. To go, VerbForm=Fin | Mood=Ind | Tense=Fut.

\begin{tabular}{|l|l|l|l|l|l|l|}
\hline Number & Person & be & can & go & do & accept \\
\hline Sing & 1 & jsem & můžu, mohu & jdu & dělám & akceptuji \\
\hline Sing & 2 & $j s i$ & můžeš & jdeš & děláš & akceptuješ \\
\hline Sing & 3 & $j e$ & může & jde & dělá & akceptuje \\
\hline Plur & 1 & jsme & můžeme & jdeme & děláme & akceptujeme \\
\hline Plur & 2 & jste & můžete & jdete & děláte & akceptujete \\
\hline Plur & 3 & jsou & můžou, mohou & jdou & dělají & akceptují \\
\hline
\end{tabular}

Table 6. [cs] VerbForm=Fin | Mood=Ind | Tense=Pres 


\begin{tabular}{|l|l|l|l|l|l|l|}
\hline Number & Person & be & can & go & do & accept \\
\hline Sing & 1 & som & môžem & idu & robím & akceptujem \\
\hline Sing & 2 & si & môžeš & ideš & robíš & akceptuješ \\
\hline Sing & 3 & je & môže & ide & robí & akceptuje \\
\hline Plur & 1 & sme & môžeme & ideme & robíme & akceptujeme \\
\hline Plur & 2 & ste & môžete & idete & robíte & akceptujete \\
\hline Plur & 3 & sú & môžu & idú & robia & akceptujú \\
\hline
\end{tabular}

Table 7. [sk] VerbForm=Fin | Mood=Ind | Tense=Pres

\begin{tabular}{|c|c|c|c|c|c|c|}
\hline Number & Person & be & can & go & do & accept \\
\hline Sing & 1 & sym & móžu & $d u$ & dźěłam & akceptuju \\
\hline Sing & 2 & sy & móžeš & dźeš & džětaš & akceptuješ \\
\hline Sing & 3 & je & móže & $d z ́ e$ & dźěta & akceptuje \\
\hline Dual & 1 & smój & móžemoj & dźemoj & dźěłamoj & akceptujemoj \\
\hline Dual & 2 & staj & móžetej & dźetej & dźětatej & akceptujetej \\
\hline Dual & 3 & staj & móžetej & dźetej & dźětatej & akceptujetej \\
\hline Plur & 1 & smy & móžemy & dźemy & dźéłamy & akceptujemy \\
\hline Plur & 2 & sće & móžeće & dźeće & džětaće & akceptujeće \\
\hline Plur & 3 & su & móža, móžeja & $d u, d z ́ e j a$ & dźéłaja & akceptuja \\
\hline
\end{tabular}

Table 8. [hsb] VerbForm=Fin | Mood=Ind | Tense=Pres

\begin{tabular}{|l|l|l|l|l|l|l|}
\hline Number & Person & be & can & go & do & accept \\
\hline Sing & 1 & jestem & mogę & idę & robię & akceptuję \\
\hline Sing & 2 & jesteś & możesz & idziesz & robisz & akceptujesz \\
\hline Sing & 3 & jest & może & idzie & robi & akceptuje \\
\hline Plur & 1 & jesteśmy & możemy & idziemy & robimy & akceptujemy \\
\hline Plur & 2 & jesteście & możecie & idziecie & robicie & akceptujecie \\
\hline Plur & 3 & sq & moga & ida & robia & akceptuja \\
\hline
\end{tabular}

Table 9. [pl] VerbForm=Fin | Mood=Ind | Tense=Pres 


\begin{tabular}{|c|c|c|c|c|c|c|}
\hline Number & Person & be & can & go & do & accept \\
\hline Sing & 1 & $\begin{array}{l}\epsilon \\
j e\end{array}$ & $\begin{array}{l}\text { можу } \\
\text { моžu }\end{array}$ & $\begin{array}{l}\breve{u} \partial y \\
j d u\end{array}$ & $\begin{array}{l}\text { роблю } \\
\text { roblju }\end{array}$ & $\begin{array}{l}\text { акцептую } \\
\text { аксертији }\end{array}$ \\
\hline Sing & 2 & \begin{tabular}{|l|}
$\epsilon c u, \epsilon$ \\
$j e s y, j e$
\end{tabular} & $\begin{array}{l}\text { можеш } \\
\text { mоžeš }\end{array}$ & $\begin{array}{l}\breve{u} \partial e m \\
j d e \check{s}\end{array}$ & $\begin{array}{l}\text { poбum } \\
\text { robyš }\end{array}$ & $\begin{array}{l}\text { акцепттуєu } \\
\text { akceptuješ }\end{array}$ \\
\hline Sing & 3 & $\begin{array}{l}\epsilon \\
j e\end{array}$ & $\begin{array}{l}\text { може } \\
\text { može }\end{array}$ & $\begin{array}{l}\breve{u} \partial e \\
j d e\end{array}$ & $\begin{array}{l}\text { poбumb } \\
\text { robyt' }\end{array}$ & $\begin{array}{l}\text { акиептуе } \\
\text { akceptuje }\end{array}$ \\
\hline Plur & 1 & $\begin{array}{l}\epsilon \\
j e\end{array}$ & $\begin{array}{l}\text { можемо } \\
\text { тоžето }\end{array}$ & $\begin{array}{l}\breve{u} \partial е м о, ~ \breve{и ̆ д е м ~} \\
\text { jdeто, jdem }\end{array}$ & $\begin{array}{l}\text { робимо, робим } \\
\text { robуто, robym }\end{array}$ & $\begin{array}{l}\text { акиептучемо } \\
\text { аксертијето }\end{array}$ \\
\hline Plur & 2 & $\begin{array}{l}\epsilon \\
j e\end{array}$ & $\begin{array}{l}\text { можете } \\
\text { možete }\end{array}$ & $\begin{array}{l}\breve{u} \text { deme } \\
\text { jdete }\end{array}$ & $\begin{array}{l}\text { poбume } \\
\text { robyte }\end{array}$ & $\begin{array}{l}\text { aкuеnmyeme } \\
\text { akceptujete }\end{array}$ \\
\hline Plur & 3 & $\begin{array}{l}E \\
j e\end{array}$ & $\begin{array}{l}\text { можутьв } \\
\text { mоžut' }\end{array}$ & $\begin{array}{l}\breve{u} \partial y m s \\
j d u t^{\prime}\end{array}$ & $\begin{array}{l}\text { роблять } \\
\text { robljat' }\end{array}$ & $\begin{array}{l}\text { акцептують } \\
\text { akсерtujut' }\end{array}$ \\
\hline
\end{tabular}

Table 10. [uk] VerbForm=Fin | Mood=Ind | Tense=Pres

\begin{tabular}{|c|c|c|c|c|c|c|}
\hline Number & Person & be & can & go & do & accept \\
\hline Sing & 1 & & $\begin{array}{l}\text { могу } \\
\text { mоgu }\end{array}$ & $\begin{array}{l}u \partial y \\
i d u\end{array}$ & $\begin{array}{l}\text { делаю } \\
\text { dеlaju }\end{array}$ & $\begin{array}{l}\text { акиептую } \\
\text { аксертији }\end{array}$ \\
\hline Sing & 2 & & $\begin{array}{l}\text { можеешь } \\
\text { mоžеš' }\end{array}$ & $\begin{array}{l}\text { uдёuь } \\
\text { idëšs }\end{array}$ & $\begin{array}{l}\text { делаешь } \\
\text { delaeš' }^{\prime}\end{array}$ & $\begin{array}{l}\text { aкuенттуешь } \\
\text { akceptueš' }\end{array}$ \\
\hline Sing & 3 & $\begin{array}{l}\text { ecmb } \\
\text { est' }\end{array}$ & $\begin{array}{l}\text { может } \\
\text { možet }\end{array}$ & $\begin{array}{l}u \partial \ddot{e} m \\
\text { idët }\end{array}$ & $\begin{array}{l}\text { deлает } \\
\text { delaet }\end{array}$ & $\begin{array}{l}\text { aкuеnтует } \\
\text { akceptuet }\end{array}$ \\
\hline Plur & 1 & & $\begin{array}{l}\text { можем } \\
\text { тоžеm }\end{array}$ & $\begin{array}{l}u \partial \ddot{e} \mathcal{M} \\
\text { idёm }\end{array}$ & $\begin{array}{l}\text { делаем } \\
\text { delaеm }\end{array}$ & $\begin{array}{l}\text { акиептуем } \\
\text { akсертиет }\end{array}$ \\
\hline Plur & 2 & & $\begin{array}{l}\text { можсете } \\
\text { možete }\end{array}$ & $\begin{array}{l}\text { uдёme } \\
\text { idëte }\end{array}$ & $\begin{array}{l}\text { делаете } \\
\text { delaete }\end{array}$ & $\begin{array}{l}\text { aкuеnтулете } \\
\text { akceptuete }\end{array}$ \\
\hline Plur & 3 & $\begin{array}{l}\text { cymb } \\
\text { sut }{ }^{\prime}\end{array}$ & $\begin{array}{l}\text { могуm } \\
\text { mogut }\end{array}$ & $\begin{array}{l}\text { uдym } \\
\text { idut }\end{array}$ & $\begin{array}{l}\text { делают } \\
\text { delajut }\end{array}$ & $\begin{array}{l}\text { акиептуют } \\
\text { akcерtujut }\end{array}$ \\
\hline
\end{tabular}

Table 11. [ru] VerbForm=Fin | Mood=Ind | Tense=Pres 


\begin{tabular}{|l|l|l|l|l|l|l|}
\hline Number & Person & be & can & go & do & accept \\
\hline Sing & 1 & sem & morem & grem & delam & akceptiram \\
\hline Sing & 2 & si & moreš & greš & delaš & akceptiraš \\
\hline Sing & 3 & je & more & gre & dela & akceptira \\
\hline Dual & 1 & sva & moreva & greva & delava & akceptirava \\
\hline Dual & 2 & sta & moreta & gresta & delata & akceptirata \\
\hline Dual & 3 & sta & moreta & gresta & delata & akceptirata \\
\hline Plur & 1 & smo & moremo & gremo & delamo & akceptiramo \\
\hline Plur & 2 & ste & morete & greste & delate & akceptirate \\
\hline Plur & 3 & so & morejo & gredo, grejo & delajo & akceptirajo \\
\hline
\end{tabular}

Table 12. [sl] VerbForm=Fin | Mood=Ind | Tense=Pres

\begin{tabular}{|c|c|c|c|c|c|c|}
\hline Number & Person & be & can & go & do & accept \\
\hline Sing & 1 & $\begin{array}{l}\text { ç̋M } \\
\text { săm }\end{array}$ & $\begin{array}{l}\text { мога } \\
\text { moga }\end{array}$ & $\begin{array}{l}\text { отивам } \\
\text { otivam }\end{array}$ & $\begin{array}{l}\text { правя } \\
\text { pravja }\end{array}$ & $\begin{array}{l}\text { акиептирам } \\
\text { akceptiram }\end{array}$ \\
\hline Sing & 2 & $\begin{array}{l}c u \\
\text { si }\end{array}$ & $\begin{array}{l}\text { можсеш } \\
\text { mоžеš }\end{array}$ & $\begin{array}{l}\text { отиваши } \\
\text { otivaš }\end{array}$ & $\begin{array}{l}\text { правищ } \\
\text { praviš }\end{array}$ & $\begin{array}{l}\text { акцептираш } \\
\text { akceptiraš }\end{array}$ \\
\hline Sing & 3 & $\begin{array}{l}e \\
e\end{array}$ & $\begin{array}{l}\text { може } \\
\text { može }\end{array}$ & $\begin{array}{l}\text { отива } \\
\text { otiva }\end{array}$ & $\begin{array}{l}\text { прави } \\
\text { pravi }\end{array}$ & $\begin{array}{l}\text { акцептира } \\
\text { akceptira }\end{array}$ \\
\hline Plur & 1 & $\begin{array}{l}\text { c.me } \\
\text { sme }\end{array}$ & $\begin{array}{l}\text { можем } \\
\text { тоžет }\end{array}$ & $\begin{array}{l}\text { отиваме } \\
\text { otivame }\end{array}$ & $\begin{array}{l}\text { правим } \\
\text { pravim }\end{array}$ & $\begin{array}{l}\text { акиептираме } \\
\text { akceptirame }\end{array}$ \\
\hline Plur & 2 & $\begin{array}{l}\text { cme } \\
\text { ste }\end{array}$ & $\begin{array}{l}\text { можете } \\
\text { možete }\end{array}$ & $\begin{array}{l}\text { omuвame } \\
\text { otivate }\end{array}$ & $\begin{array}{l}\text { npaвume } \\
\text { pravite }\end{array}$ & $\begin{array}{l}\text { aкцептирате } \\
\text { akceptirate }\end{array}$ \\
\hline Plur & 3 & $\begin{array}{l}c a \\
s a\end{array}$ & $\begin{array}{l}\text { могаm } \\
\text { mogat }\end{array}$ & $\begin{array}{l}\text { oтиват } \\
\text { otivat }\end{array}$ & $\begin{array}{l}\text { правяm } \\
\text { pravjat }\end{array}$ & $\begin{array}{l}\text { акиептират } \\
\text { akceptirat }\end{array}$ \\
\hline
\end{tabular}

Table 13. [bg] VerbForm=Fin | Mood=Ind | Tense=Pres 


\begin{tabular}{|l|l|l|l|l|l|l|}
\hline Number & Person & be & can & go & do & accept \\
\hline Sing & 1 & jesam, sam & mogu & idem & delam & akceptiram \\
\hline Sing & 2 & jesi, si & možeš & ideš & delaš & akceptiraš \\
\hline Sing & 3 & jest, je & može & ide & dela & akceptira \\
\hline Plur & 1 & jesmo, smo & možemo & idemo & delamo & akceptiramo \\
\hline Plur & 2 & jeste, ste & možete & idete & delate & akceptirate \\
\hline Plur & 3 & jesu, su & mogu & idu & delaju & akceptiraju \\
\hline
\end{tabular}

Table 14. [hr] VerbForm=Fin | Mood=Ind | Tense=Pres

\begin{tabular}{|c|c|c|c|c|c|}
\hline Number & Person & be & can & go & do \\
\hline Sing & 1 & $\begin{array}{l}\text { Есмь } \\
\text { jesmb }\end{array}$ & $\begin{array}{l}\text { могж } \\
\operatorname{mog} Q\end{array}$ & $\begin{array}{l}\mathrm{HAX}, 1 \mathrm{~A} \times \\
i d \varphi\end{array}$ & $\begin{array}{l}\text { АБцањж } \\
\text { dělajo }\end{array}$ \\
\hline Sing & 2 & $\begin{array}{l}\mathrm{ECH} \\
\text { jesi }\end{array}$ & $\begin{array}{l}\text { МоЖЕшН } \\
\text { mоžeši }\end{array}$ & $\begin{array}{l}\text { НАЕШН, } 1 \text { ІЕШН } \\
\text { ideši }\end{array}$ & $\begin{array}{l}\text { АъиаЕшн } \\
\text { dělaješi }\end{array}$ \\
\hline Sing & 3 & $\begin{array}{l}\text { Естъ } \\
\text { jestz }\end{array}$ & $\begin{array}{l}\text { МоЖЕТъ } \\
\text { možetъ }\end{array}$ & $\begin{array}{l}\text { НАЕТъ, ІАЕТЬ } \\
\text { idetъ }\end{array}$ & $\begin{array}{l}\text { АЂ Аахтъ } \\
\text { dělaatъ }\end{array}$ \\
\hline Dual & 1 & $\begin{array}{l}\text { Есвњ } \\
\text { jesvě }\end{array}$ & $\begin{array}{l}\text { МОЖЕВЂ } \\
\text { mоževе̌ }\end{array}$ & $\begin{array}{l}\text { НАЕВЂ, 1АЕВБ } \\
\text { idevě }\end{array}$ & $\begin{array}{l}\text { АБиаЕвњ } \\
\text { dělajevě }\end{array}$ \\
\hline Dual & 2 & $\begin{array}{l}\text { вста } \\
\text { jesta }\end{array}$ & $\begin{array}{l}\text { можета } \\
\text { možeta }\end{array}$ & $\begin{array}{l}\text { HАETA, IAETd } \\
\text { ideta }\end{array}$ & $\begin{array}{l}\text { АЂ } а \text { аЕта } \\
\text { dělajeta }\end{array}$ \\
\hline Dual & 3 & $\begin{array}{l}\text { EсTE } \\
\text { jeste }\end{array}$ & $\begin{array}{l}\text { MOЖETE } \\
\text { možete }\end{array}$ & $\begin{array}{l}\text { HAETE, IAETE } \\
\text { idete }\end{array}$ & $\begin{array}{l}\text { АЂへАЕTЕ } \\
\text { dělajete }\end{array}$ \\
\hline Plur & 1 & $\begin{array}{l}\text { Есмъ } \\
\text { jesmъ }\end{array}$ & $\begin{array}{l}\text { МоЖЕМъ } \\
\text { mоžеmъ }\end{array}$ & $\begin{array}{l}\text { НАЕМЪ, ІАЕМЪ } \\
\text { idem } 6\end{array}$ & $\begin{array}{l}\text { АъиаЕмъ } \\
\text { dělajemъ }\end{array}$ \\
\hline Plur & 2 & $\begin{array}{l}\text { ЕстЕ } \\
\text { jeste }\end{array}$ & $\begin{array}{l}\text { MожетЕ } \\
\text { možete }\end{array}$ & $\begin{array}{l}\text { HAETE, IAETE } \\
\text { idete }\end{array}$ & $\begin{array}{l}\text { АЂムAETE } \\
\text { dělajete }\end{array}$ \\
\hline Plur & 3 & $\begin{array}{l}\text { схть } \\
\text { sqtr }\end{array}$ & $\begin{array}{l}\text { могхтъ } \\
\text { mogetz }\end{array}$ & $\begin{array}{l}\text { НАХтъ, 1АХТъ } \\
\text { idotъ }\end{array}$ & $\begin{array}{l}\text { Аъцањжть } \\
\text { dělajotz }\end{array}$ \\
\hline
\end{tabular}

Table 15. [cu] VerbForm=Fin | Mood=Ind | Tense=Pres 


\section{Imperative}

[cs] rozkazovací způsob (imperativ); [sk] imperatív (rozkazovací spôsob); [hsb] imperativ; [pl] tryb rozkazujacy; [uk] наказовий спосіб; [ru] повелительное наклонение; [sl] velelnik, velelni naklon; [hr] imperativ; [bg] повелително наклонение (императив). Tables 16-25.

Imperative is a simple finite verb form that marks person and number but it does not mark tense (we leave the Tense feature empty). Imperative forms are not available in the $3^{\text {rd }}$ person (appeals to third persons may be formed periphrastically, using particles and present indicative forms; these are not annotated as imperatives). Imperative also does not exist in the $1^{\text {st }}$ person singular. Modal verbs usually do not have imperatives.

\begin{tabular}{|l|l|l|l|l|l|}
\hline Number & Person & be & go & do & accept \\
\hline Sing & 2 & bud' & jdi, pojd' & dělej & akceptuj \\
\hline Plur & 1 & bud'me & jděme, pojd'me & dělejme & akceptujme \\
\hline Plur & 2 & bud'te & jděte, pojd'te & dělejte & akceptujte \\
\hline
\end{tabular}

Table 16. [cs] VerbForm=Fin | Mood=Imp

\begin{tabular}{|l|l|l|l|l|l|}
\hline Number & Person & be & go & do & accept \\
\hline Sing & 2 & bud' & chod' & rob & akceptuj \\
\hline Plur & 1 & bud'me & chod'me & robme & akceptujme \\
\hline Plur & 2 & bud'te & chod'te & robte & akceptujte \\
\hline
\end{tabular}

Table 17. [sk] VerbForm=Fin | Mood=Imp

\begin{tabular}{|l|l|l|l|l|l|}
\hline Number & Person & be & go & do & accept \\
\hline Sing & 2 & budź & dźi, póndź & dźěłaj & akceptuj \\
\hline Dual & 1 & budźmoj & dźemoj, póndźmoj & dźéłajmoj & akceptujmoj \\
\hline Dual & 2 & budźtej & dźetej, póndźtej & dźéłajtej & akceptujtej \\
\hline Plur & 1 & budźmy & dźemy, póndźmy & dźéłajmy & akceptujmy \\
\hline Plur & 2 & budźće & dźé́e, póńdźće & džéłajće & akceptujće \\
\hline
\end{tabular}

Table 18. [hsb] VerbForm=Fin | Mood=Imp 


\begin{tabular}{|l|l|l|l|l|l|}
\hline Number & Person & be & go & do & accept \\
\hline Sing & 2 & bądź & idź & rób & akceptuj \\
\hline Plur & 1 & bądźmy & idźmy & róbmy & akceptujmy \\
\hline Plur & 2 & bądźcie & idźcie & róbcie & akceptujcie \\
\hline
\end{tabular}

Table 19. [pl] VerbForm=Fin | Mood=Imp

\begin{tabular}{|c|c|c|c|c|c|}
\hline Number & Person & be & go & do & accept \\
\hline Sing & 2 & $\begin{array}{l}\text { бydb } \\
\text { bud' }\end{array}$ & $\begin{array}{l}\breve{u} \partial u \\
j d y\end{array}$ & $\begin{array}{l}\text { poбu } \\
\text { roby }\end{array}$ & $\begin{array}{l}\text { акцептуй } \\
\text { аксерtuj }\end{array}$ \\
\hline Plur & 1 & $\begin{array}{l}б y \partial ь м о \\
\text { bud'mo }\end{array}$ & $\begin{array}{l}\breve{u} \partial i_{\text {мо }}, \breve{u} \partial i_{\mathcal{M}} \\
\text { jdimo, jdim }\end{array}$ & $\begin{array}{l}\text { робімо, робім } \\
\text { robimo, robim }\end{array}$ & $\begin{array}{l}\text { акцептуймо } \\
\text { akсерtијто }\end{array}$ \\
\hline Plur & 2 & $\begin{array}{l}\text { бydbme } \\
\text { bud'te }\end{array}$ & $\begin{array}{l}\breve{u} \partial i m b \\
\text { jdit' }\end{array}$ & $\begin{array}{l}\text { poбimb } \\
\text { robit' }\end{array}$ & $\begin{array}{l}\text { aкцептуйте } \\
\text { akceptujte }\end{array}$ \\
\hline
\end{tabular}

Table 20. [uk] VerbForm=Fin | Mood=Imp

\begin{tabular}{|c|c|c|c|c|c|}
\hline Number & Person & be & go & do & accept \\
\hline Sing & 2 & $\begin{array}{l}\sigma y \partial z \\
\text { bud' }\end{array}$ & $\begin{array}{l}u \partial u \\
i d i\end{array}$ & $\begin{array}{l}\text { делай } \\
\text { delaj }\end{array}$ & $\begin{array}{l}\text { акиептуй } \\
\text { akceptuj }\end{array}$ \\
\hline Plur & 1 & $\begin{array}{l}\text { бyдемте } \\
\text { budemte }\end{array}$ & $\begin{array}{l}\text { uдёмme } \\
\text { idëmte }\end{array}$ & $\begin{array}{l}\text { делаемте } \\
\text { delaemte }\end{array}$ & $\begin{array}{l}\text { aкuептуемте } \\
\text { akceptuemte }\end{array}$ \\
\hline Plur & 2 & $\begin{array}{l}\text { бydzme } \\
\text { bud'te }\end{array}$ & $\begin{array}{l}\text { udume } \\
\text { idite }\end{array}$ & $\begin{array}{l}\text { deлайme } \\
\text { delajte }\end{array}$ & $\begin{array}{l}\text { aкuеnтуйте } \\
\text { akceptujte }\end{array}$ \\
\hline
\end{tabular}

Table 21. [ru] VerbForm=Fin | Mood=Imp 


\begin{tabular}{|l|l|l|l|l|l|}
\hline Number & Person & be & go & do & accept \\
\hline Sing & 2 & bodi & pojdi & delaj & akceptiraj \\
\hline Dual & 1 & bodiva & pojdiva & delajva & akceptirajva \\
\hline Dual & 2 & bodita & pojdita & delajta & akceptirajta \\
\hline Plur & 1 & bodimo & pojdimo & delajmo & akceptirajmo \\
\hline Plur & 2 & bodite & pojdite & delajte & akceptirajte \\
\hline
\end{tabular}

Table 22. [sl] VerbForm=Fin | Mood=Imp

\begin{tabular}{|l|l|l|l|l|l|}
\hline Number & Person & be & go & do & accept \\
\hline Sing & 2 & budi & idi & delaj & akceptiraj \\
\hline Plur & 1 & budimo & idimo & delajmo & akceptirajmo \\
\hline Plur & 2 & budite & idite & delajte & akceptirajte \\
\hline
\end{tabular}

Table 23. [hr] VerbForm=Fin | Mood=Imp

\begin{tabular}{|c|c|c|c|c|c|}
\hline Number & Person & be & go & do & accept \\
\hline Sing & 2 & $\begin{array}{l}\text { бъдu } \\
\text { bădi }\end{array}$ & $\begin{array}{l}\text { отивац̆ } \\
\text { otivaj }\end{array}$ & $\begin{array}{l}\text { прави } \\
\text { pravi }\end{array}$ & $\begin{array}{l}\text { акцептирай } \\
\text { akceptiraj }\end{array}$ \\
\hline Plur & 2 & $\begin{array}{l}\text { бrдeme } \\
\text { bădete }\end{array}$ & $\begin{array}{l}\text { omивайте } \\
\text { otivajte }\end{array}$ & $\begin{array}{l}\text { правете } \\
\text { pravete }\end{array}$ & $\begin{array}{l}\text { aкцептирайте } \\
\text { akceptirajte }\end{array}$ \\
\hline
\end{tabular}

Table 24. [bg] VerbForm=Fin | Mood=Imp

\begin{tabular}{|c|c|c|c|c|}
\hline Number & Person & be & go & do \\
\hline Sing & 2 & $\begin{array}{l}\text { БЖАН } \\
b o d i\end{array}$ & $\begin{array}{l}\mathrm{HAH}, \mathrm{LAH} \\
i d i\end{array}$ & $\begin{array}{l}\text { АЂ } а \mathrm{\alpha H} \\
\text { dělai }\end{array}$ \\
\hline Dual & 2 & $\begin{array}{l}\text { БХАєта } \\
\text { boděta }\end{array}$ & $\begin{array}{l}\text { НАБТА, ІаБта } \\
\text { iděta }\end{array}$ & $\begin{array}{l}\text { АЂланта } \\
\text { dělaita }\end{array}$ \\
\hline Plur & 2 & $\begin{array}{l}\text { БХАЂтЕ } \\
\text { boděte }\end{array}$ & $\begin{array}{l}\text { НАЂTЕ, 1АБТЕ } \\
\text { iděte }\end{array}$ & $\begin{array}{l}\text { АЂムанте } \\
\text { dělaite }\end{array}$ \\
\hline
\end{tabular}

Table 25. [cu] VerbForm=Fin | Mood=Imp 


\section{Aorist Indicative}

[cs] aorist; [hsb] preteritum; [hr] aorist (pređašnje svršeno vreme); $[\mathrm{bg}]$ минало свтршено време. Tables $\underline{26}, \underline{32}, \underline{28}$ and $\underline{30}$.

Aorist is the old Slavic simple past tense. It is a finite form that marks person and number of the subject. It existed in the Old Church Slavonic language and it has survived in several languages until today; however, many languages have replaced it by the l-participle. For example, aorist is attested in Old Czech but it vanished during the $15^{\text {th }}$ century.

Aorist is regularly used (together with imperfect, see Section 9) in Bulgarian and Macedonian. It is still understood in Serbian and Croatian, albeit its usage is limited. Aorist has also survived in the Sorbian languages, where it has effectively merged with imperfect into one simple past called preterite. Unlike in Bulgarian, in Sorbian the forms stemming from aorist are only found with perfective verbs, and the historical forms of imperfect only with imperfective verbs $\underline{-}$ (Breu, 2000). Hence we have just two inflection patterns, instead of two different tenses.

We can use the simple Tense=Past feature to annotate aorist in Slavic languages as it does not collide with the other past forms. This has been the original intention in Interset and in Universal Dependencies and it is used currently both in the Old Church Slavonic and the Bulgarian data. On the other hand, UD Ancient Greek uses a language-specific value Tense=Aor; if the future versions of the universal guidelines adopt this value, it might be more appropriate to use it.

The Sorbian preterite will be also tagged Tense=Past, regardless whether the verb is perfective or imperfective.

\section{Imperfect Indicative}

[cs] imperfektum; [hr] imperfekat (pređašnje nesvršeno vreme); [bg] минало несвършено време. Tables 27,29 and 31 .

Imperfect is another simple past tense that only survived in a few languages. It does not have any equivalent in English, but there are imperfect tenses in Romance languages.

For the merged aorist-imperfect (preterite) in Sorbian languages, see Section 8 .

Verbs in imperfect describe states or actions that were happening during some past moment. They may or may not continue at and after the moment of speaking. Important is the past context and the relation of the action (state) to some other action (state) happening in the past.

Despite the name, both imperfective and perfective verbs can be used in the imperfect tense! Perfective verbs in the imperfect tense denote actions that were repeated in

\footnotetext{
${ }^{8}$ It could be argued that the Sorbian usage is prototypical, while the imperfect tense of perfective verbs in Bulgarian is marked. Nevertheless, such change of perspective would have no impact on our proposed analysis.
} 


\begin{tabular}{|l|l|l|l|l|l|l|}
\hline Number & Person & be & can & go & do & accept \\
\hline Sing & 1 & bych & možech & jid & dělach & přijiech \\
\hline Sing & 2 & by & može & jide & děla & přijie \\
\hline Sing & 3 & by & može & jide & děla & přijie \\
\hline Dual & 1 & bychově & možechově & jidově & dělachově & přijiechově \\
\hline Dual & 2 & bysta & možesta & jideta & dělasta & přijiesta \\
\hline Dual & 3 & bysta & možesta & jideta & dělasta & přijiesta \\
\hline Plur & 1 & bychom & možechom & jidom & dělachom & přijiechom \\
\hline Plur & 2 & byste & možeste & jidete & dělaste & přijieste \\
\hline Plur & 3 & bychu & možechu & jidú & dělachu & přijiechu \\
\hline
\end{tabular}

Table 26. Old [cs] VerbForm=Fin | Mood=Ind | Tense=Past

\begin{tabular}{|l|l|l|l|l|l|l|}
\hline Number & Person & be & can & go & do & accept \\
\hline Sing & 1 & biech & možiech & jdiech & dělajiech & přijiech \\
\hline Sing & 2 & bieše & možieše & jdieše & dělajieše & přijieše \\
\hline Sing & 3 & bieše & možieše & jdieše & dělajieše & přijieše \\
\hline Dual & 1 & biechově & možiechově & jdiechově & dělajiechově & přijiechově \\
\hline Dual & 2 & biešta & možiešta & jdiešta & dělajiešta & přijiešta \\
\hline Dual & 3 & biešta & možiešta & jdiešta & dělajiešta & přijiešta \\
\hline Plur & 1 & biechom & možiechom & jdiechom & dělajiechom & přijiechom \\
\hline Plur & 2 & biešte & možiešte & jdiešte & dělajiešte & přijiešte \\
\hline Plur & 3 & biechu & možiechu & jdiechu & dělajiechu & přijiechu \\
\hline
\end{tabular}

Table 27. Old [cs] VerbForm=Fin | Mood=Ind | Tense=Imp

the past. Hence the Aspect feature should not be used to mark this tense. As discussed in Section 4, that feature should be reserved to denote the lexical aspect of Slavic verbs, bound to their lemma. Instead, Universal Features provide a feature dedicated to the imperfect tense, Tense $=$ Imp.

Examples [bg]:

- Kогато се прибрах вкъщи, децата вече сnяха. (Kogato se pribrah vkăšti, decata veče spjaha) "When I came home, the children were already asleep."

- Щом дойдеше, веднага запалваше цигара. (Štom dojdeše, vednaga zapalvaše cigara.) "Every time he came, he always lit a cigarette." 


\begin{tabular}{|c|c|c|c|c|c|c|}
\hline Number & Person & be & can & go & do & accept \\
\hline Sing & 1 & $\begin{array}{l}\text { бяx } \\
\text { bjah }\end{array}$ & $\begin{array}{l}\text { можсах } \\
\text { mоžah }\end{array}$ & $\begin{array}{l}\text { отивах } \\
\text { otivah }\end{array}$ & $\begin{array}{l}\text { правих } \\
\text { pravih }\end{array}$ & $\begin{array}{l}\text { акцептирах } \\
\text { akceptirah }\end{array}$ \\
\hline Sing & 2 & $\begin{array}{l}\text { беше, бе } \\
\text { beše, be }\end{array}$ & $\begin{array}{l}\text { можа } \\
\text { тоža }\end{array}$ & $\begin{array}{l}\text { отива } \\
\text { otiva }\end{array}$ & $\begin{array}{l}\text { прави } \\
\text { pravi }\end{array}$ & $\begin{array}{l}\text { акцептира } \\
\text { akceptira }\end{array}$ \\
\hline Sing & 3 & $\begin{array}{l}\text { беше, бе } \\
\text { beše, be }\end{array}$ & $\begin{array}{l}\text { можа } \\
\text { mоža }\end{array}$ & $\begin{array}{l}\text { omuвa } \\
\text { otiva }\end{array}$ & $\begin{array}{l}\text { прави } \\
\text { pravi }\end{array}$ & $\begin{array}{l}\text { акцептира } \\
\text { akceptira }\end{array}$ \\
\hline Plur & 1 & $\begin{array}{l}\text { бяхме } \\
\text { bjahme }\end{array}$ & $\begin{array}{l}\text { можахме } \\
\text { mоžahme }\end{array}$ & $\begin{array}{l}\text { omивахме } \\
\text { otivahme }\end{array}$ & $\begin{array}{l}\text { правихме } \\
\text { pravihme }\end{array}$ & $\begin{array}{l}\text { акцептирахме } \\
\text { akceptirahme }\end{array}$ \\
\hline Plur & 2 & $\begin{array}{l}\text { 6axme } \\
\text { bjahte }\end{array}$ & $\begin{array}{l}\text { можахте } \\
\text { možahte }\end{array}$ & $\begin{array}{l}\text { omuвахте } \\
\text { otivahte }\end{array}$ & $\begin{array}{l}\text { nравихте } \\
\text { pravihte }\end{array}$ & $\begin{array}{l}\text { aкuеnтирахте } \\
\text { akceptirahte }\end{array}$ \\
\hline Plur & 3 & $\begin{array}{l}\text { бaxa } \\
\text { bjaha }\end{array}$ & $\begin{array}{l}\text { можаха } \\
\text { mоžaha }\end{array}$ & $\begin{array}{l}\text { отиваха } \\
\text { otivaha }\end{array}$ & $\begin{array}{l}\text { правиха } \\
\text { praviha }\end{array}$ & $\begin{array}{l}\text { акцептираха } \\
\text { akceptiraha }\end{array}$ \\
\hline
\end{tabular}

Table 28. [bg] VerbForm=Fin | Mood=Ind | Tense=Past

\begin{tabular}{|c|c|c|c|c|c|c|}
\hline Number & Person & be & can & go & do & accept \\
\hline Sing & 1 & $\begin{array}{l}\text { бax } \\
\text { bjah }\end{array}$ & $\begin{array}{l}\text { можсех } \\
\text { mоžeh }\end{array}$ & $\begin{array}{l}\text { omuваx } \\
\text { otivah }\end{array}$ & $\begin{array}{l}\text { правех } \\
\text { praveh }\end{array}$ & $\begin{array}{l}\text { акцептирах } \\
\text { akceptirah }\end{array}$ \\
\hline Sing & 2 & $\begin{array}{l}\text { беше, бе } \\
\text { beše, be }\end{array}$ & $\begin{array}{l}\text { можеше } \\
\text { mоžеše }\end{array}$ & $\begin{array}{l}\text { omuвame } \\
\text { otivaše }\end{array}$ & $\begin{array}{l}\text { правеше } \\
\text { praveše }\end{array}$ & $\begin{array}{l}\text { aкцептираше } \\
\text { akceptiraše }\end{array}$ \\
\hline Sing & 3 & $\begin{array}{l}\text { беше, бе } \\
\text { beše, be }\end{array}$ & $\begin{array}{l}\text { можеше } \\
\text { mоžеše }\end{array}$ & $\begin{array}{l}\text { omuвame } \\
\text { otivaše }\end{array}$ & $\begin{array}{l}\text { правеше } \\
\text { praveše }\end{array}$ & $\begin{array}{l}\text { aкцептираше } \\
\text { akceptiraše }\end{array}$ \\
\hline Plur & 1 & $\begin{array}{l}\text { бяхме } \\
\text { bjahme }\end{array}$ & $\begin{array}{l}\text { можехме } \\
\text { mоžehme }\end{array}$ & $\begin{array}{l}\text { omuвахме } \\
\text { otivahme }\end{array}$ & $\begin{array}{l}\text { правехме } \\
\text { pravehme }\end{array}$ & $\begin{array}{l}\text { aкцептирахме } \\
\text { akceptirahme }\end{array}$ \\
\hline Plur & 2 & $\begin{array}{l}\text { Gaxme } \\
\text { bjahte }\end{array}$ & $\begin{array}{l}\text { можехте } \\
\text { možehte }\end{array}$ & $\begin{array}{l}\text { omusaxme } \\
\text { otivahte }\end{array}$ & $\begin{array}{l}\text { npaвexme } \\
\text { pravehte }\end{array}$ & $\begin{array}{l}\text { aкuеnтuрахте } \\
\text { akceptirahte }\end{array}$ \\
\hline Plur & 3 & $\begin{array}{l}\text { бaxa } \\
\text { bjaha }\end{array}$ & $\begin{array}{l}\text { можеха } \\
\text { možeha }\end{array}$ & $\begin{array}{l}\text { omuвaxa } \\
\text { otivaha }\end{array}$ & $\begin{array}{l}\text { правеха } \\
\text { praveha }\end{array}$ & $\begin{array}{l}\text { aкцептираха } \\
\text { akceptiraha }\end{array}$ \\
\hline
\end{tabular}

Table 29. [bg] VerbForm=Fin | Mood=Ind | Tense=Imp 


\begin{tabular}{|c|c|c|c|c|c|}
\hline Number & Person & be & can & go & do \\
\hline Sing & 1 & $\begin{array}{l}\text { Быхъ } \\
\text { bych }\end{array}$ & $\begin{array}{l}\text { могъ } \\
\text { mogъ }\end{array}$ & $\begin{array}{l}\mathrm{HA} \mathrm{b}, \mathrm{LA} \mathrm{b} \\
i d \tau\end{array}$ & $\begin{array}{l}\text { АЂیахъ } \\
\text { dělachヶ }\end{array}$ \\
\hline Sing & 2 & $\begin{array}{l}\text { Быстъ } \\
\text { bystz }\end{array}$ & $\begin{array}{l}\text { МожЕ } \\
\text { može }\end{array}$ & $\begin{array}{l}\mathrm{HAE}, \mathrm{LAE} \\
\text { ide }\end{array}$ & $\begin{array}{l}\text { АЂ АашЕ } \\
\text { dělaše }\end{array}$ \\
\hline Sing & 3 & $\begin{array}{l}\text { Быстъ, ьы } \\
\text { bystъ, by }\end{array}$ & $\begin{array}{l}\text { МожЕ } \\
\text { može }\end{array}$ & $\begin{array}{l}\mathrm{HAE}, \mathrm{IAE} \\
\text { ide }\end{array}$ & $\begin{array}{l}\text { АЂへашЕ } \\
\text { dělaše }\end{array}$ \\
\hline Dual & 1 & $\begin{array}{l}\text { выховъ } \\
\text { bychově }\end{array}$ & $\begin{array}{l}\text { моговъ } \\
\text { mogově }\end{array}$ & $\begin{array}{l}\text { НАОВъ, ІАОВъ } \\
\text { idově }\end{array}$ & $\begin{array}{l}\text { АЂцаховъ } \\
\text { dělachově }\end{array}$ \\
\hline Dual & 2 & $\begin{array}{l}\text { выста } \\
\text { bysta }\end{array}$ & $\begin{array}{l}\text { МожЕта } \\
\text { možeta }\end{array}$ & $\begin{array}{l}\text { HAETA, LAETA } \\
\text { ideta }\end{array}$ & $\begin{array}{l}\text { АЂласта } \\
\text { dělasta }\end{array}$ \\
\hline Dual & 3 & $\begin{array}{l}\text { высте } \\
\text { byste }\end{array}$ & $\begin{array}{l}\text { МожЕтЕ } \\
\text { možete }\end{array}$ & $\begin{array}{l}\text { HAETE, IAETE } \\
\text { idete }\end{array}$ & $\begin{array}{l}\text { АЂ АастЕ } \\
\text { dělaste }\end{array}$ \\
\hline Plur & 1 & $\begin{array}{l}\text { ьыхомъ } \\
\text { bychomъ }\end{array}$ & $\begin{array}{l}\text { могомъ } \\
\text { mogomъ }\end{array}$ & $\begin{array}{l}\text { НАОМъ, ІАОМъ } \\
\text { idomъ }\end{array}$ & $\begin{array}{l}\text { АЂیахомъ } \\
\text { dělachomヶ }\end{array}$ \\
\hline Plur & 2 & $\begin{array}{l}\text { высте } \\
\text { byste }\end{array}$ & $\begin{array}{l}\text { можетЕ } \\
\text { možete }\end{array}$ & $\begin{array}{l}\text { HAETE, LAETE } \\
\text { idete }\end{array}$ & $\begin{array}{l}\text { АЂласте } \\
\text { dělaste }\end{array}$ \\
\hline Plur & 3 & $\begin{array}{l}\text { БышА } \\
\text { byšę }\end{array}$ & $\begin{array}{l}\text { могх } \\
\operatorname{mog} Q\end{array}$ & $\begin{array}{l}\text { HAX, } 1 A K \\
i d Q\end{array}$ & 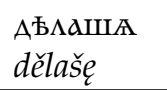 \\
\hline
\end{tabular}

Table 30. [cu] VerbForm=Fin | Mood=Ind | Tense=Past 


\begin{tabular}{|c|c|c|c|c|c|}
\hline Numb & $P$ & be & can & go & do \\
\hline Sing & 1 & $\begin{array}{l}\text { БЂХъ } \\
\text { běch }\end{array}$ & $\begin{array}{l}\text { мождахъ } \\
\text { možaachъ }\end{array}$ & $\begin{array}{l}\text { НАЂахъ, 1АЂахъ } \\
\text { iděachъ }\end{array}$ & $\begin{array}{l}\text { Аъ Аахъъ } \\
\text { dělaachъ }\end{array}$ \\
\hline Sing & 2 & $\begin{array}{l}\text { БЪ } \\
b \check{e}\end{array}$ & $\begin{array}{l}\text { можааше } \\
\text { možaаše }\end{array}$ & $\begin{array}{l}\text { НАБаШЕ, ІАЂАШЕ } \\
\text { iděaše }\end{array}$ & $\begin{array}{l}\text { АЂরдаше } \\
\text { dělaaše }\end{array}$ \\
\hline Sing & 3 & $\begin{array}{l}\text { Бъ, БЂаше } \\
b \check{e}, \text { běaše }\end{array}$ & $\begin{array}{l}\text { можааше } \\
\text { možaaše }\end{array}$ & $\begin{array}{l}\text { НАЂашЕ, 1АЂашЕ } \\
\text { iděaše }\end{array}$ & $\begin{array}{l}\text { АЂরдаше } \\
\text { dělaaše }\end{array}$ \\
\hline Dual & 1 & $\begin{array}{l}\text { Бъховњ } \\
\text { běchově }\end{array}$ & $\begin{array}{l}\text { можааховъ } \\
\text { mоžaachově }\end{array}$ & $\begin{array}{l}\text { НАъаховъ, 1Аъаховъ } \\
\text { iděachové }\end{array}$ & $\begin{array}{l}\text { Аєиааховє } \\
\text { dělaachově }\end{array}$ \\
\hline Dual & 2 & $\begin{array}{l}\text { БЂста } \\
\text { běsta }\end{array}$ & $\begin{array}{l}\text { можаашета } \\
\text { možaašeta }\end{array}$ & $\begin{array}{l}\text { НАБаШЕТА, 1АБАШЕТА } \\
\text { iděašeta }\end{array}$ & $\begin{array}{l}\text { АЂ } \\
\text { dělaašeta }\end{array}$ \\
\hline Dual & 3 & $\begin{array}{l}\text { БЂАШЕТЕ, БЂстЕ } \\
\text { běašete, běste }\end{array}$ & $\begin{array}{l}\text { можаашете } \\
\text { možaašete }\end{array}$ & $\begin{array}{l}\text { НАБашЕTЕ, 1АЂАШЕТЕ } \\
\text { iděašete }\end{array}$ & $\begin{array}{l}\text { АЂ } \\
\text { dělaašete }\end{array}$ \\
\hline Plur & 1 & $\begin{array}{l}\text { БЂхомъ } \\
\text { běchomъ }\end{array}$ & $\begin{array}{l}\text { можаххомъ } \\
\text { mоžaachomъ }\end{array}$ & $\begin{array}{l}\text { нАъахомъ, цаъахомъ } \\
\text { iděachomъ }\end{array}$ & $\begin{array}{l}\text { Аъиадхомъ } \\
\text { dělaachomъ }\end{array}$ \\
\hline Plur & 2 & $\begin{array}{l}\text { БЂстЕ } \\
\text { běste }\end{array}$ & $\begin{array}{l}\text { МОЖАаШЕTE } \\
\text { možaašete }\end{array}$ & $\begin{array}{l}\text { НАБаШЕTЕ, ІАЂДШЕТЕ } \\
\text { iděašete }\end{array}$ & $\begin{array}{l}\text { АЂ } \\
\text { dělaašete }\end{array}$ \\
\hline Plur & 3 & $\begin{array}{l}\text { БЂахк, БЂшА } \\
\text { běacho, běšę }\end{array}$ & $\begin{array}{l}\text { можаdхж } \\
\text { možaach }\end{array}$ & $\begin{array}{l}\text { HАЂахж, 1АЂахж } \\
\text { iděacho }\end{array}$ & $\begin{array}{l}\text { АЂ } \mathbf{d a x 及 ~} \\
\text { dělaach }\end{array}$ \\
\hline
\end{tabular}

Table 31. [cu] VerbForm=Fin | Mood=Ind | Tense=Imp

\begin{tabular}{|c|c|c|c|c|c|c|}
\hline Number & Person & be & can & go & do & accept \\
\hline Sing & 1 & běch & móžech & džěch & dźěłach & akceptowach \\
\hline Sing & 2 & běše & móžeše & 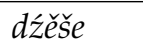 & dźěłaše & akceptowaše \\
\hline Sing & 3 & běše & móžeše & dźěše & dźěłaše & akceptowaše \\
\hline Dual & 1 & běchmoj & móžechmoj & džěmoj & dźéłachmoj & akceptowachmoj \\
\hline Dual & 2 & běštej & móžeštej & džěštej & dźéłaštej & akceptowaštej \\
\hline Dual & 3 & běštej & móžeštej & dźěštej & dźětaštej & akceptowaštej \\
\hline Plur & 1 & běchmy & móžechmy & dźěchmy & dźěłachmy & akceptowachmy \\
\hline Plur & 2 & běšće & móžešće & dźěšće & džětašće & akceptowašce \\
\hline Plur & 3 & bе̌chu & móžechu & dźěchu & dźéłachu & akceptowachu \\
\hline
\end{tabular}

Table 32. [hsb] VerbForm=Fin | Mood=Ind | Tense=Past 


\section{Active Participle and Past Tense}

[cs] př̌čestí činné, minulý čas; [sk] minulý čas; [hsb] l-forma, perfekt; [pl] czas przeszly; [uk] минулий иас; [ru] прошедшее время; [sl] opisni deležnik na -l, preteklik; [hr] glagolski pridjev radni, prošlo vreme; $[\mathrm{bg}]$ минало деятелно свършено причастие, минало деятелно несвтриено причастие. Tables 33-42.

The typical formation of the past tense in most (but not all) modern Slavic languages is periphrastic, using a finite form of the auxiliary verb to be and the active participle (as opposed to the passive participle). The participle may also be called past participle because of its close ties to the past tense, and despite the fact that it is also used to form conditional or even the future tense. Sometimes the participle itself is called past tense (it makes sense because in some languages the auxiliary verb is omitted). Or it is simply called l-participle because its suffixes typically involve the consonant $-l$.

Early stages of Slavic languages (and those modern stages that retained the aorist) understand the constructions with the 1-participle as perfect tenses that we know in English. Present perfect, past perfect and future perfect may be constructed, depending on the form of the auxiliary verb. Interestingly, the periphrastic past tense is also termed préteritum in Modern Czech (Academia, 1986), but the term perfektum prevails when Old Czech is described (Komárek et al., 1967) (cf. Präterium = Imperfekt vs. Perfekt in German).

Like other Slavic participles, the 1-participle marks gender and number. Typically it has only the short form that is used in predicates, it does not inflect for case and is tagged VERB or AUX. Occasional long forms exist but they are considered derived adjectives and tagged ADJ. The derivation is not productive. It applies mainly to intransitive perfective verbs, while the passive participle would be used with transitive verbs for the same purpose. Example [cs]: spadly "the one who fell down", shnily "rotten", poklesly "dropped". Annotating VerbForm of the derived adjective is purely optional. The short, predicative form should always have VerbForm=Part.

Voice=Act should also be always present so that the participle is distinguished from the passive participle.

Some Bulgarian verbs have two 1-participles (past participles): perfect and imperfect. We cannot use the Aspect feature to distinguish them because the feature is bound to lemma, and an imperfective verb can have both perfect and imperfect participles. Nevertheless, the distinction is an analogy to the distinction between the two simple past tenses, and we will use the Tense feature to distinguish the participles. The default is Tense=Past (for past perfect participles). Past imperfect participles will get Tense=Imp.

It is less clear whether the 1-participle should be annotated with Tense=Past in the other languages, in which it is not necessary to distinguish different types of 1participles. In many Slavic languages (especially the northern ones) this is the promi- 


\begin{tabular}{|l|l|l|l|l|l|l|l|}
\hline Number & Gender & Animacy & be & can & go & do & accept \\
\hline Sing & Masc & & byl & mohl & šel & dělal & akceptoval \\
\hline Sing & Fem & & byla & mohla & šla & dělala & akceptovala \\
\hline Sing & Neut & & bylo & mohlo & šlo & dělalo & akceptovalo \\
\hline Plur & Masc & Anim & byli & mohli & šli & dělali & akceptovali \\
\hline Plur & Masc & Inan & byly & mohly & šly & dělaly & akceptovaly \\
\hline Plur & Fem & & byla & mohla & šla & dělala & akceptovala \\
\hline Plur & Neut & & byt
\end{tabular}

Table 33. [cs] VERB, AUX | VerbForm=Part | Voice=Act | Tense=Past

\begin{tabular}{|l|l|l|l|l|l|l|}
\hline Number & Gender & be & can & go & do & accept \\
\hline Sing & Masc & bol & mohol & išiel & robil & akceptoval \\
\hline Sing & Fem & bola & mohla & išla & robila & akceptovala \\
\hline Sing & Neut & bolo & mohlo & išlo & robilo & akceptovalo \\
\hline Plur & & boli & mohli & išli & robili & akceptovali \\
\hline
\end{tabular}

Table 34. [sk] VERB, AUX | VerbForm=Part | Voice=Act | Tense=Past

nent and default function of the 1-participle. .9 Even in languages where it is used in periphrastic perfect tenses (which co-exist with simple past tenses), the perfect or resultative meaning implies that the action happened in the past, although the past is relative to a point in time that may be different from the moment of speaking. Therefore we recommend to include Tense=Past in the annotation.

See Section 18 for the annotation of 1-participles used in the current UD datasets.

In Slovenian and Serbo-Croatian, the finite form of the auxiliary is used with all persons and numbers: Je šel $v$ šolo. "He went to the school." Sem šel v šolo. "I went to the school." In Czech and Slovak, the finite form of the auxiliary is omitted in the $3^{\text {rd }}$ person: Šel do školy. "He went to the school." Šel jsem do školy. "I went to the school." In Ukrainian and Russian, the auxiliary is omitted in all persons. That is why the subject cannot be dropped in Russian. The person could be understood from a finite verb but not from the participle, hence we need a personal pronoun: Oн пошел

\footnotetext{
${ }^{9}$ As mentioned above, it is also used in conditional and in some languages even in the future tense. Still, we are looking for distinctive features of individual words rather than of the periphrastic expressions. In a Slavic-wide perspective, Past seems as close as we can get without defining a language-specific feature for 1-participles.
} 


\begin{tabular}{|l|l|l|l|l|l|l|}
\hline Number & Gender & be & can & go & do & accept \\
\hline Sing & Masc & był & mohł & šoł & dźěłał & akceptował \\
\hline Sing & Fem & była & móhła & šła & dźěłała & akceptowała \\
\hline Sing & Neut & było & móhło & šło & dźěłało & akceptowało \\
\hline Dual & & byłoj & móhłoj & šłoj & dźěłałoj & akceptowałoj \\
\hline Plur & & byli & móhli & šli & dźěłali & akceptowali \\
\hline
\end{tabular}

Table 35. [hsb] VERB,AUX | VerbForm=Part | Voice=Act | Tense=Past

\begin{tabular}{|c|c|c|c|c|c|c|c|}
\hline Number & Gender & Animacy & be & can & go & do & accept \\
\hline Sing & Masc & & byt & mógt & szedt & robit & akceptowat \\
\hline Sing & Fem & & była & mogła & szła & robiła & akceptowała \\
\hline Sing & Neut & & było & mogto & szło & robiło & akceptowało \\
\hline Plur & Masc & Anim & byli & mogli & szli & robili & akceptowali \\
\hline Plur & Masc & Nhum & \multirow{4}{*}{ byty } & \multirow{4}{*}{ mogty } & \multirow{4}{*}{ szty } & \multirow{4}{*}{ robity } & \multirow{4}{*}{ akceptowaty } \\
\hline Plur & Masc & Inan & & & & & \\
\hline Plur & Fem & & & & & & \\
\hline Plur & Neut & & & & & & \\
\hline
\end{tabular}

Table 36. [pl] VERB,AUX | VerbForm=Part | Voice=Act | Tense=Past

в школу. (On pošel v školu.) "Hе went to the school." Я пошел в школу. (Ja pošel v školu.) "I went to the school."

In Polish, the auxiliary and the participle have merged in one past-tense form. However, they can also attach to a preceding word: Cieszę się, żeś zrozumiał. "I am glad that you have understood." (The auxiliary -ś is attached to a conjunction.) Myśmy nie wiedzieli, że przyjada. "We did not know they were coming." (Attached to a pronoun.) That is why the tokenization in the Polish treebank cuts off the finite morpheme as a separate syntactic word of a special type called "agglutination". We keep this approach to tokenization, emphasizing the parallelism between the Polish data and the other Slavic languages: Poszedt do szkoły. "He went to the school." Poszedt-em do szkoły. "I went to the school." (The hyphen in the second example indicates tokenization but it does not appear in the surface text.)

Note that there are other types of participles that could be (and sometimes are) called active participles. See Section 13 for details. 


\begin{tabular}{|c|c|c|c|c|c|c|}
\hline Number & Gender & be & can & go & do & accept \\
\hline Sing & Masc & $\begin{array}{l}\text { бyв } \\
\text { buv }\end{array}$ & $\begin{array}{l}\text { мiz } \\
\text { mih }\end{array}$ & 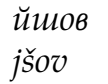 & $\begin{array}{l}\text { робив } \\
\text { robyv }\end{array}$ & $\begin{array}{l}\text { акцептував } \\
\text { akсерtuvav }\end{array}$ \\
\hline Sing & Fem & $\begin{array}{l}\text { була } \\
\text { bula }\end{array}$ & $\begin{array}{l}\text { могла } \\
\text { mohla }\end{array}$ & $\begin{array}{l}\breve{u ̆ л л а ~} \\
\text { jšla }\end{array}$ & $\begin{array}{l}\text { робила } \\
\text { robyla }\end{array}$ & $\begin{array}{l}\text { акцептувала } \\
\text { akceptuvala }\end{array}$ \\
\hline Sing & Neut & $\begin{array}{l}\text { було } \\
\text { bulo }\end{array}$ & $\begin{array}{l}\text { могло } \\
\text { mohlo }\end{array}$ & 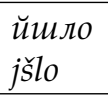 & $\begin{array}{l}\text { робило } \\
\text { robylo }\end{array}$ & $\begin{array}{l}\text { акцептувало } \\
\text { akсертибalo }\end{array}$ \\
\hline Plur & & $\begin{array}{l}\text { були } \\
\text { buly }\end{array}$ & $\begin{array}{l}\text { могли } \\
\text { mohly }\end{array}$ & $\begin{array}{l}\text { ŭwлu } \\
\text { jšly }\end{array}$ & $\begin{array}{l}\text { робили } \\
\text { robyly }\end{array}$ & $\begin{array}{l}\text { акцептували } \\
\text { akcерtuvaly }\end{array}$ \\
\hline
\end{tabular}

Table 37. [uk] VERB, AUX | VerbForm=Part | Voice=Act | Tense=Past

\begin{tabular}{|c|c|c|c|c|c|c|}
\hline Number & Gender & be & can & go & do & accept \\
\hline Sing & Masc & $\begin{array}{l}\sigma b \imath \pi \\
b y l\end{array}$ & $\begin{array}{l}\text { MO2 } \\
\text { mog }\end{array}$ & $\begin{array}{l}\text { mёл } \\
\text { š̈ll }\end{array}$ & $\begin{array}{l}\text { делал } \\
\text { delal }\end{array}$ & $\begin{array}{l}\text { акцептовал } \\
\text { akceptoval }\end{array}$ \\
\hline Sing & Fem & $\begin{array}{l}\text { билла } \\
\text { byla }\end{array}$ & $\begin{array}{l}\text { могла } \\
\text { mogla }\end{array}$ & $\begin{array}{l}\text { uлra } \\
\text { šla }\end{array}$ & $\begin{array}{l}\text { делала } \\
\text { delala }\end{array}$ & $\begin{array}{l}\text { акцептовала } \\
\text { akceptovala }\end{array}$ \\
\hline Sing & Neut & $\begin{array}{l}\text { билло } \\
\text { bylo }\end{array}$ & $\begin{array}{l}\text { могло } \\
\text { moglo }\end{array}$ & $\begin{array}{l}\text { шло } \\
\text { šlo }\end{array}$ & $\begin{array}{l}\text { делало } \\
\text { delalo }\end{array}$ & $\begin{array}{l}\text { акцептовало } \\
\text { akсер tovalo }\end{array}$ \\
\hline Plur & & $\begin{array}{l}\text { бияли } \\
\text { byli }\end{array}$ & $\begin{array}{l}\text { могли } \\
\text { mogli }\end{array}$ & $\begin{array}{l}\text { us } l i \\
\text { si }\end{array}$ & $\begin{array}{l}\text { делали } \\
\text { delali }\end{array}$ & $\begin{array}{l}\text { акиептовали } \\
\text { akceptovali }\end{array}$ \\
\hline
\end{tabular}

Table 38. [ru] VERB,AUX | VerbForm=Part | Voice=Act | Tense=Past

\begin{tabular}{|l|l|l|l|l|l|l|}
\hline Number & Gender & be & can & go & do & accept \\
\hline Sing & Masc & bio & mogao & šao & delao & akceptirao \\
\hline Sing & Fem & bila & mogla & šla & delala & akceptirala \\
\hline Sing & Neut & bilo & moglo & šlo & delalo & akceptiralo \\
\hline Plur & Masc & bili & mogli & šli & delali & akceptirali \\
\hline Plur & Fem & bile & mogle & šle & delale & akceptirale \\
\hline Plur & Neut & bila & mogla & šla & delala & akceptirala \\
\hline
\end{tabular}

Table 39. [hr] VERB,AUX | VerbForm=Part | Voice=Act | Tense=Past 


\begin{tabular}{|c|c|c|c|c|c|c|}
\hline Number & Gender & be & can & go & do & accept \\
\hline Sing & Masc & bil & mogel & šel & delal & akceptiral \\
\hline Sing & Fem & bila & mogla & šla & delala & akceptirala \\
\hline Sing & Neut & bilo & moglo & šlo & delalo & akceptiralo \\
\hline Dual & Masc & bila & mogla & šla & delala & akceptirala \\
\hline Dual & Fem & \multirow{2}{*}{ bili } & \multirow{2}{*}{ mogli } & \multirow{2}{*}{ šli } & \multirow{2}{*}{ delali } & \multirow{2}{*}{ akceptirali } \\
\hline Dual & Neut & & & & & \\
\hline Plur & Masc & bili & $m o g l i$ & šli & delali & akceptirali \\
\hline Plur & Fem & bile & mogle & šle & delale & akceptirale \\
\hline Plur & Neut & bila & mogla & šla & delala & akceptirala \\
\hline
\end{tabular}

Table 40. [sl] VERB, AUX | VerbForm=Part | Voice=Act | Tense=Past

\begin{tabular}{|c|c|c|c|c|c|c|c|}
\hline Tense & Number & Gender & be & can & go & do & accept \\
\hline Past & Sing & Masc & $\begin{array}{l}\text { бuл } \\
\text { bil }\end{array}$ & $\begin{array}{l}\text { могъл } \\
\text { mogăl }\end{array}$ & $\begin{array}{l}\text { отивал } \\
\text { otival }\end{array}$ & $\begin{array}{l}\text { правил } \\
\text { pravil }\end{array}$ & $\begin{array}{l}\text { акцептирал } \\
\text { akceptiral }\end{array}$ \\
\hline Past & Sing & Fem & $\begin{array}{l}\text { била } \\
\text { bila }\end{array}$ & $\begin{array}{l}\text { могла } \\
\text { mogla }\end{array}$ & $\begin{array}{l}\text { отивала } \\
\text { otivala }\end{array}$ & $\begin{array}{l}\text { правила } \\
\text { pravila }\end{array}$ & $\begin{array}{l}\text { акцептирала } \\
\text { akceptirala }\end{array}$ \\
\hline Past & Sing & Neut & $\begin{array}{l}\text { било } \\
\text { bilo }\end{array}$ & $\begin{array}{l}\text { могло } \\
\text { moglo }\end{array}$ & $\begin{array}{l}\text { отивало } \\
\text { otivalo }\end{array}$ & $\begin{array}{l}\text { правило } \\
\text { pravilo }\end{array}$ & $\begin{array}{l}\text { акцептирало } \\
\text { akceptiralo }\end{array}$ \\
\hline Past & Plur & & $\begin{array}{l}\text { били } \\
\text { bili }\end{array}$ & $\begin{array}{l}\text { могли } \\
\text { mogli }\end{array}$ & $\begin{array}{l}\text { отивали } \\
\text { otivali }\end{array}$ & $\begin{array}{l}\text { правили } \\
\text { pravili }\end{array}$ & $\begin{array}{l}\text { акцептирали } \\
\text { akceptirali }\end{array}$ \\
\hline Imp & Sing & Masc & & $\begin{array}{l}\text { можел } \\
\text { mоžel }\end{array}$ & & $\begin{array}{l}\text { правел } \\
\text { pravel }\end{array}$ & \\
\hline Imp & Sing & Fem & & $\begin{array}{l}\text { можела } \\
\text { mоžela }\end{array}$ & & $\begin{array}{l}\text { правела } \\
\text { pravela }\end{array}$ & \\
\hline Imp & Sing & Neut & & $\begin{array}{l}\text { можело } \\
\text { тоžеlo }\end{array}$ & & $\begin{array}{l}\text { правело } \\
\text { pravelo }\end{array}$ & \\
\hline Imp & Plur & & & $\begin{array}{l}\text { можели } \\
\text { тоželi }\end{array}$ & & $\begin{array}{l}\text { правели } \\
\text { praveli }\end{array}$ & \\
\hline
\end{tabular}

Table 41. [bg] VERB, AUX | VerbForm=Part | Voice=Act 


\begin{tabular}{|c|c|c|c|c|c|}
\hline Number & Gender & be & can & go & do \\
\hline Sing & Masc & $\begin{array}{l}\text { Былъ } \\
\text { bylz }\end{array}$ & $\begin{array}{l}\text { могАъ } \\
\text { moglъ }\end{array}$ & 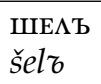 & 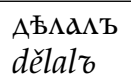 \\
\hline Sing & Fem & $\begin{array}{l}\text { въла } \\
\text { byla }\end{array}$ & $\begin{array}{l}\text { могла } \\
\text { mogla }\end{array}$ & $\begin{array}{l}\text { шیd } \\
\text { šla }\end{array}$ & $\begin{array}{l}\text { АЂıаıd } \\
\text { dělala }\end{array}$ \\
\hline Sing & Neut & $\begin{array}{l}\text { выло } \\
\text { bylo }\end{array}$ & $\begin{array}{l}\text { МогАО } \\
\text { moglo }\end{array}$ & $\begin{array}{l}\text { Шیо } \\
\text { šlo }\end{array}$ & $\begin{array}{l}\text { АЂムаıо } \\
\text { dělalo }\end{array}$ \\
\hline Dual & Masc & $\begin{array}{l}\text { вылд } \\
\text { byla }\end{array}$ & $\begin{array}{l}\text { могла } \\
\text { mogla }\end{array}$ & $\begin{array}{l}\text { шیd } \\
\text { šla }\end{array}$ & $\begin{array}{l}\text { АЂıаıd } \\
\text { dělala }\end{array}$ \\
\hline \multirow{2}{*}{ Dual } & Fem & \multirow{2}{*}{$\begin{array}{l}\text { Бъмъ } \\
\text { bylě }\end{array}$} & \multirow{2}{*}{$\begin{array}{l}\text { могАњ } \\
\text { moglě }\end{array}$} & \multirow{2}{*}{ 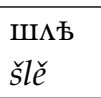 } & \multirow{2}{*}{ 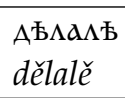 } \\
\hline & Neut & & & & \\
\hline Plur & Masc & $\begin{array}{l}\text { вы н } \\
\text { byli }\end{array}$ & $\begin{array}{l}\text { могАн } \\
\text { mogli }\end{array}$ & $\begin{array}{l}\omega \Lambda \mathrm{H} \\
\text { Šli }\end{array}$ & 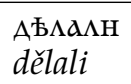 \\
\hline Plur & Fem & $\begin{array}{l}\text { Былы } \\
\text { byly }\end{array}$ & $\begin{array}{l}\text { могАы } \\
\text { mogly }\end{array}$ & $\begin{array}{l}\text { шиы } \\
\text { šly }\end{array}$ & 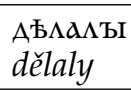 \\
\hline Plur & Neut & $\begin{array}{l}\text { выла } \\
\text { byla }\end{array}$ & $\begin{array}{l}\text { могла } \\
\text { mogla }\end{array}$ & $\begin{array}{l}\text { шیa } \\
\text { šla }\end{array}$ & $\begin{array}{l}\text { АЂムaıd } \\
\text { dělala }\end{array}$ \\
\hline
\end{tabular}

Table 42. [cu] VERB, AUX | VerbForm=Part | Voice=Act | Tense=Past

\begin{tabular}{|c|c|c|c|c|c|c|c|c|c|}
\hline Number & \multicolumn{3}{|c|}{ Sing } & \multicolumn{3}{|c|}{ Dual } & \multicolumn{3}{|c|}{ Plur } \\
\hline Person & 1 & 2 & 3 & 1 & 2 & 3 & 1 & 2 & 3 \\
\hline CS & bych & bys & $b y$ & & & & bychom & byste & $b y$ \\
\hline sk & \multicolumn{9}{|c|}{$b y$} \\
\hline hsb & bych & $b y$ & by & bychmoj & byštej & byštej & bychmy & byšće & bychu \\
\hline pl & $-b y m$ & $-b y s ́$ & $-b y$ & & & & -byśmy & -byście & $-b y$ \\
\hline uk & \multicolumn{9}{|c|}{$\begin{array}{l}\sigma, \sigma u \\
b, b y\end{array}$} \\
\hline $\mathrm{ru}$ & \multicolumn{9}{|c|}{$\begin{array}{c}\sigma b l, 6 \\
b y, b\end{array}$} \\
\hline sl & \multicolumn{9}{|c|}{$b i$} \\
\hline $\mathrm{hr}$ & bih & $b i$ & $b i$ & & & & bismo & biste & $b i$ \\
\hline $\mathrm{bg}$ & $\begin{array}{l}\text { 6ux } \\
\text { bih }\end{array}$ & $\begin{array}{l}6 u \\
b i\end{array}$ & $\begin{array}{l}6 u \\
b i\end{array}$ & & & & $\begin{array}{l}\text { бихме } \\
\text { bihme }\end{array}$ & $\begin{array}{l}\text { ouxme } \\
\text { bihte }\end{array}$ & $\begin{array}{l}\text { бuxa } \\
\text { biha }\end{array}$ \\
\hline $\mathrm{cu}$ & $\begin{array}{l}\text { Бнмь } \\
\text { bimb }\end{array}$ & $\begin{array}{l}\text { 6H } \\
b i\end{array}$ & $\begin{array}{l}\text { Бн } \\
b i\end{array}$ & $\begin{array}{l}\text { Бнвњ } \\
\text { bivě }\end{array}$ & $\begin{array}{l}\text { внста } \\
\text { bista }\end{array}$ & $\begin{array}{l}\text { Бнсте } \\
\text { biste }\end{array}$ & $\begin{array}{l}\text { Бнмъ } \\
\text { bimъ }\end{array}$ & $\begin{array}{l}\text { Бнсте } \\
\text { biste }\end{array}$ & $\begin{array}{l}\text { Бж, БншА } \\
b q, \text { bišę }\end{array}$ \\
\hline
\end{tabular}

Table 43. To be, AUX | VerbForm=Fin | Mood=Cnd. 


\section{Conditional}

[cs] podmiňovací zpưsob; [sk] podmieňovací spôsob; [hsb] konjunktiw; [pl] tryb przypиszczajacy; [uk] умовний спосіб; [ru] условное наклонение, кондиционал; [sl] pogojnik; [hr] mogućni način, potencijal [bg] условно наклонение. Table 43.

The conditional mood (both present and past) is formed periphrastically using the active (1-) participle of the content verb and a special form of the auxiliary verb to be. The auxiliary form is annotated Mood=Cnd, the participle is not. The Tense feature of the auxiliary is empty. Some languages have present and past conditional but the difference is expressed analytically and the same auxiliary form is used in both.

The auxiliary form is finite and in some languages (e.g. Czech) it inflects for number and person. In other languages (e.g. Russian) it has been reduced to a single frozen form that is used in all persons and numbers. Some authors may prefer to tag the frozen auxiliary as particle (PART), but we suggest that it be tagged AUX, with the verb to be as its lemma, to keep the annotation parallel across Slavic languages.

In Slovak and Slovenian, the reduced particle-like conditional auxiliary by / bi is used and combined with the present indicative auxiliary exactly as for the past tense (all persons in Slovenian, only $1^{\text {st }}$ and $2^{\text {nd }}$ in Slovak). The present auxiliary is written separately. Similar analysis can be done in Polish where the present auxiliary takes the form of the agglutinating morpheme (cf. Section 10) but is treated as an independent syntactic word: potrafili-by-śmy "we would be able".

Sometimes the conditional auxiliary merges with a subordinating conjunction as in Czech aby "so that", kdyby "if", Polish żebyście "so that you", gdybyśmy "if we", or Russian uтобы (čtoby) "so that". According to the UD guidelines we should split such fusions back into syntactic words in the annotation (umo-6bl).

\section{Adverbial Participle (Transgressive)}

[cs] přechodnîk přtomný, prechodník minulý; [sk] prechodnik; [hsb] transgresiw; [pl] imiesłów przysłówkowy wspótczesny, imiesłów przysłówkowy uprzedni; [uk] diєnрислівник теперішнъого иасу, дієприслівник минулого иасу; [ru] дееприиастие настоящего времени, деепричастие промедшего времени; [sl] deležje; [hr] glagolski prilog sadašnji, glagolski prilog prošli; $[\mathrm{bg}]$ деenрuиacmue. Tables $\underline{4} \underline{4} \underline{52}$.

Adverbial participles, also called transgressives, verbal adverbs, converbs (Nedjalkov and Nedjalkov, 1987) or even gerunds (Comrie and Corbett, 2001), $\underline{10}$ are nonfinite forms of verbs that can be used as adverbial modifiers in a clause. The circumstance they specify is that the action of the main verb happens while the action of the

\footnotetext{
${ }^{10}$ The term gerund may cause confusion: in English it is close to verbal nouns (cf. Section 16), in Romance languages the term denotes present participles. The term transgressive is unique but it is not widely known. We can encounter it in descriptions of Czech and the Sorbian languages; more generally, its usage is limited to the German-Slavic linguistic tradition. We use the term here because it is part of the UD guidelines v1, encoded as the feature VerbForm=Trans.
} 


\begin{tabular}{|l|l|l|l|l|l|l|l|}
\hline Tense & Number & Gender & be & can & go/come & do & accept \\
\hline Pres & Sing & Masc & jsa & moha & jda & dělaje & akceptuje \\
\hline Pres & Sing & Fem,Neut & jsouc & mohouc & jdouc & dělajíc & akceptujic \\
\hline Pres & Plur & & jsouce & mohouce & jdouce & dělajíce & akceptujíce \\
\hline Past & Sing & Masc & byv & & přišed & udělav & akceptovav \\
\hline Past & Sing & Fem,Neut & byvši & & přišedši & udělavši & akceptovavši \\
\hline Past & Plur & & byvše & & přišedše & udělavše & akceptovavše \\
\hline
\end{tabular}

Table 44. [CS] VERB, AUX | VerbForm=Trans. Plural forms do not distinguish gender. The present and past transgressives in the "go/come" and "do" columns are forms of different lemmas (imperfective vs. perfective).

\begin{tabular}{|l|l|l|l|l|}
\hline be & can & go & do & accept \\
\hline súc & môžúc & idúc & robiac & akceptujúc \\
\hline
\end{tabular}

Table 45. [sk] VERB,AUX | VerbForm=Trans | Tense=Pres. Modern Slovak has only the present transgressive.

\begin{tabular}{|l|l|l|l|l|l|}
\hline Tense & be & can & go/come & do & accept \\
\hline Pres & & móžo & dźejo & dźéłajo, dźěłajcy & akceptujo, akceptujcy \\
\hline Past & bywši & & póšowši, póšedši & nadźéławši & akceptowawši \\
\hline
\end{tabular}

Table 46. [hsb] VERB, AUX | VerbForm=Trans. The present and past transgressives in the "do" column are forms of different lemmas (imperfective vs. perfective).

transgressive is happening (present transgressive), or that it happens after the action of the transgressive has happened (past transgressive). The subject of the clause and of the transgressive is identical.

Present transgressives tend to be created from imperfective verbs and past transgressives from perfective verbs, but exceptions exist (Academia, 1986, p. 154). Again, Aspect should be fixed to lemma and not used to distinguish the two transgressives. The Tense feature should be used instead.

Transgressives are tagged VERB or AUX but not ADV, and their features include VerbForm=Trans. In some languages they mark gender and number of the subject. In others they don't. 


\begin{tabular}{|l|l|l|l|l|l|}
\hline Tense & be & can & go/come & do & accept \\
\hline Pres & będacc & mogac & idąc & robiąc & akceptując \\
\hline Past & bywszy & & poszedtszy & zrobiwszy & akceptowawszy \\
\hline
\end{tabular}

Table 47. [pl] VERB, AUX | VerbForm=Trans. The present and past transgressives in the "go" and "do" columns are forms of different lemmas (imperfective vs. perfective).

\begin{tabular}{|c|c|c|c|c|c|}
\hline Tense & be & can & go/come & do & accept \\
\hline Pres & $\begin{array}{l}\text { будучu } \\
\text { budučy }\end{array}$ & $\begin{array}{l}\text { можсучи } \\
\text { тоžис̌у }\end{array}$ & $\begin{array}{l}\breve{u} \partial y u u \\
\text { jdučy }\end{array}$ & $\begin{array}{l}\text { роблячи } \\
\text { robljačy }\end{array}$ & $\begin{array}{l}\text { акцептуючи } \\
\text { аксерtијисуу }\end{array}$ \\
\hline Past & $\begin{array}{l}\text { бувшu } \\
\text { buvšy }\end{array}$ & $\begin{array}{l}\text { могши } \\
\text { mohšy }\end{array}$ & $\begin{array}{l}\text { прийщовщи } \\
\text { pryjšоvšy }\end{array}$ & $\begin{array}{l}\text { зробивши } \\
\text { zrobyvšy }\end{array}$ & $\begin{array}{l}\text { акцептувавши } \\
\text { аксерtuvavšy }\end{array}$ \\
\hline
\end{tabular}

Table 48. [UK] VERB, AUX | VerbForm=Trans. The present and past transgressives in the "go/come" and "do" columns are forms of different lemmas (imperfective vs. perfective).

\begin{tabular}{|c|c|c|c|c|c|}
\hline Tense & be & can & go/come & do & accept \\
\hline Pres & $\begin{array}{l}\text { будучu } \\
\text { buduči }\end{array}$ & & $\begin{array}{l}u \partial \mathcal{A} \\
i d j a\end{array}$ & $\begin{array}{l}\text { делая } \\
\text { delaja }\end{array}$ & $\begin{array}{l}\text { акцептуля } \\
\text { akceptuja }\end{array}$ \\
\hline Past & $\begin{array}{l}\text { бъıв, биıвщи } \\
\text { byv, byvši }\end{array}$ & $\begin{array}{l}\text { могши } \\
\text { mogši }\end{array}$ & $\begin{array}{l}\text { medwu } \\
\text { šedši }\end{array}$ & $\begin{array}{l}\text { делав, делавши } \\
\text { delav, delavši }\end{array}$ & $\begin{array}{l}\text { акцептовавии } \\
\text { akсерtоvагši }\end{array}$ \\
\hline
\end{tabular}

Table 49. [ru] VERB, AUX | VerbForm=Trans.

\begin{tabular}{|l|l|l|l|l|l|}
\hline Tense & be & can & go/come & do & accept \\
\hline Pres & bodoč & & idoč & delaje & akceptiraje \\
\hline Past & bivši & & prišedši & dodelavši & akceptiravši \\
\hline
\end{tabular}

Table 50. [sl] VERB, AUX | VerbForm=Trans. The present and past transgressives in the "go/come" and "do" columns are forms of different lemmas (imperfective vs. perfective). 


\begin{tabular}{|l|l|l|l|l|l|}
\hline Tense & be & can & go/come & do & accept \\
\hline Pres & budući & mogući & idući & delajući & akceptirajući \\
\hline Past & bivši & & došavši & dodelavši & akceptiravši \\
\hline
\end{tabular}

Table 51. [hr] VERB, AUX | VerbForm=Trans. The present and past transgressives in the "go/come" and "do" columns are forms of different lemmas (imperfective vs. perfective).

\begin{tabular}{|c|c|c|c|c|}
\hline be & can & go & do & accept \\
\hline $\begin{array}{l}\text { бъдейки, бидейки } \\
\text { bӑdеjki, bidejki }\end{array}$ & $\begin{array}{l}\text { можец̆ки } \\
\text { mоžеjki }\end{array}$ & $\begin{array}{l}\text { отивайки } \\
\text { otivajki }\end{array}$ & $\begin{array}{l}\text { правец̆ки } \\
\text { pravejki }\end{array}$ & $\begin{array}{l}\text { aкцептирайки } \\
\text { akceptirajki }\end{array}$ \\
\hline
\end{tabular}

Table 52. [bg] VERB, AUX | VerbForm=Trans.

\section{Verbal Adjective or Active Participle}

[cs] př́idavné jméno slovesné činné (zpřídavnělý přechodník); [sk] činné príčastie; [hsb] prezensowy particip; [pl] imiesłów przymiotnikowy czynny; [uk] активний дієприкметник; [ru] действительное причастие; [sl] deležnik na -̌̌, -ši; [hr] particip, glagolski pridjev; [bg] сегашно деятелно причастие. Tables 53-61.

Active verbal adjectives (or participles) correspond to transgressives (see Section 12) and are different from the active 1-participle (see Section 10). They are used attributively (not predicatively) and inflect for Case, except for $\bar{B}$ ulgarian that has neither long participles nor cases.

They should be tagged ADJ, not VERB or AUX, although their derivation from verbs is quite productive. Their lemma is the nominative singular form of the adjective, not the infinitive of the verb.

Optionally their relation to verbs may be documented using the features of VerbForm=Part, Voice=Act, Aspect (same as the aspect of the base verb) and Tense (whether they correspond to present or past transgressive). The meaning directly follows from the transgressive: [cs] dělající "one who is doing" (present verbal adjective); udělavší "one who has done" (past verbal adjective).

In standard Ukrainian, active verbal adjectives are considered ungrammatical, being a consequence of russification. $\underline{11}$

\footnotetext{
${ }^{11}$ http://nl.ijs.si/ME/V4/msd/html/msd.A-uk.html\#msd-body. 1 div. 3 div.11 div. 5 div. 1
} 


\begin{tabular}{|c|c|c|c|c|c|}
\hline Number & \multicolumn{4}{|c|}{ Sing } & Plur \\
\hline Gender & \multicolumn{2}{|c|}{ Masc } & Neut & Fem & \\
\hline Animacy & Anim & Inan & & & \\
\hline Nom & \multicolumn{3}{|c|}{ dělající } & \multirow{7}{*}{ dělající } & dělající \\
\hline Gen & \multicolumn{3}{|c|}{ dělajícího } & & dělajících \\
\hline Dat & \multicolumn{3}{|c|}{ dělajícímu } & & dělajícím \\
\hline ACC & dělajícího & děl & ijící & & dělající \\
\hline Voc & \multicolumn{3}{|c|}{ dělající } & & dělající \\
\hline LoC & \multicolumn{3}{|c|}{ dělajícím } & & dělajících \\
\hline Ins & \multicolumn{3}{|c|}{ dělajícím } & & dělajícími \\
\hline
\end{tabular}

Table 53. [cs] ADJ | Aspect=Imp | VerbForm=Part | Voice=Act | Tense=Pres. The adjective dělající means "doing" and is derived from the imperfective verb dělat "to do". The corresponding past adjective is udělavší, it is derived from the perfective verb udèlat and uses the same suffixes.

\begin{tabular}{|c|c|c|c|c|c|c|c|}
\hline Number & \multicolumn{4}{|c|}{ Sing } & \multicolumn{3}{|c|}{ Plur } \\
\hline Gender & \multicolumn{2}{|c|}{ Masc } & Neut & Fem & \multicolumn{2}{|c|}{ Masc } & Fem, Neut \\
\hline Animacy & Anim & Inan & & & Anim & Inan & \\
\hline Nom & \multicolumn{2}{|c|}{ robiaci } & robiace & robiaca & robiaci & \multicolumn{2}{|c|}{ robiace } \\
\hline Gen & \multicolumn{3}{|c|}{ robiaceho } & robiacej & \multicolumn{3}{|c|}{ robiacich } \\
\hline Dat & \multicolumn{3}{|c|}{ robiacemu } & robiacej & \multicolumn{3}{|c|}{ robiacim } \\
\hline$A C C$ & robiaceho & robiaci & robiace & robiacu & robiacich & & obiace \\
\hline LoC & \multicolumn{3}{|c|}{ robiacom } & robiacej & \multicolumn{3}{|c|}{ robiacich } \\
\hline Ins & \multicolumn{3}{|c|}{ robiacim } & robiacou & \multicolumn{3}{|c|}{ robiacimi } \\
\hline
\end{tabular}

Table 54. [sk] ADJ | Aspect=Imp | VerbForm=Part | Voice=Act | Tense=Pres. The adjective robiaci means "doing" and is derived from the imperfective verb robit' "to do". The corresponding past adjective is robivší with similar suffixes. 


\begin{tabular}{|c|c|c|c|c|c|c|c|c|c|c|}
\hline $\mathrm{Nu}$ & \multicolumn{4}{|c|}{ Sing } & \multicolumn{3}{|c|}{ Dual } & \multicolumn{3}{|c|}{ Plur } \\
\hline $\mathrm{Ge}$ & \multicolumn{2}{|c|}{ Masc } & Neut & Fem & \multicolumn{2}{|c|}{ Masc } & F., N. & \multicolumn{2}{|l|}{ Masc } & F., N. \\
\hline An & An. & In. & & & An. & In. & & An. & In. & \\
\hline Nom & \multicolumn{2}{|c|}{ dzeétacy } & dźéłace & dźěłaca & dźěłacaj & & Eéłacej & dźéłaci & & zéłace \\
\hline Gen & \multicolumn{3}{|c|}{ dźéłaceho } & dźěłaceje & \multicolumn{3}{|c|}{ dźéłaceju } & \multicolumn{3}{|c|}{ dźéłacych } \\
\hline Dat & \multicolumn{3}{|c|}{ dźěłacemu } & dźěłacej & \multicolumn{3}{|c|}{ dźěłacymaj } & \multicolumn{3}{|c|}{ dźěłacym } \\
\hline AcC & dźěłaceho & dźěłacy & dźěłace & dźěłacu & dźěłaceju & & Ěłacej & dźěłacych & & źěłace \\
\hline LoC & \multicolumn{3}{|c|}{ dźěłacym } & dźěłacej & \multicolumn{3}{|c|}{ dźěłacymaj } & \multicolumn{3}{|c|}{ dźěłacych } \\
\hline Ins & \multicolumn{3}{|c|}{ dźěłacym } & dźěłacej & \multicolumn{3}{|c|}{ dźěłacymaj } & \multicolumn{3}{|c|}{ dźétacymi } \\
\hline
\end{tabular}

Table 55. [hsb] ADJ | Aspect=Imp | VerbForm=Part | Voice=Act | Tense=Pres. The adjective dźěłacy means "doing" and is derived from the imperfective verb dźěłać "to do".

\begin{tabular}{|c|c|c|c|c|c|c|c|}
\hline \multirow{3}{*}{$\begin{array}{c}\text { Number } \\
\text { Gender } \\
\text { Animacy }\end{array}$} & \multicolumn{4}{|c|}{ Sing } & \multicolumn{3}{|c|}{ Plur } \\
\hline & \multicolumn{2}{|c|}{ Masc } & Neut & Fem & \multicolumn{2}{|c|}{ Masc } & \multirow[t]{2}{*}{ Fem, Neut } \\
\hline & Anim, Nhum & Inan & & & Anim & Nhum, Inan & \\
\hline Nom & \multicolumn{2}{|c|}{ robiący } & robiace & robiaca & robiacy & \multicolumn{2}{|c|}{ robiace } \\
\hline Gen & \multicolumn{3}{|c|}{ robiacego } & robiacej & \multicolumn{3}{|c|}{ robiacych } \\
\hline Dat & \multicolumn{3}{|c|}{ robiacemu } & robiacej & \multicolumn{3}{|c|}{ robiacym } \\
\hline AcC & robiacego & robiacy & robiace & robiaca & robiacych & \multicolumn{2}{|c|}{ robiace } \\
\hline Voc & \multicolumn{2}{|c|}{ robiacy } & robiace & robiaca & robiacy & rob & iace \\
\hline LoC & \multicolumn{3}{|c|}{ robiacym } & robiącej & \multicolumn{3}{|c|}{ robiacych } \\
\hline Ins & \multicolumn{3}{|c|}{ robiacym } & robiaca & \multicolumn{3}{|c|}{ robiacymi } \\
\hline
\end{tabular}

Table 56. [pl] ADJ | Aspect=Imp | VerbForm=Part | Voice=Act | Tense=Pres. The adjective robiący means "doing" and is derived from the imperfective verb robić "to do". The corresponding past adjective is zrobiwszy, it is derived from the perfective verb zrobić and uses the same suffixes. 


\begin{tabular}{|c|c|c|c|c|c|}
\hline Number & \multicolumn{4}{|c|}{ Sing } & Plur \\
\hline Gender & \multicolumn{2}{|c|}{ Masc } & Neut & Fem & \\
\hline Animacy & Anim & Inan & & & \\
\hline Nom & \multicolumn{2}{|c|}{$\begin{array}{c}\text { делаюший } \\
\text { delajuščij }\end{array}$} & $\begin{array}{l}\text { делаюшее } \\
\text { delajuščee }\end{array}$ & $\begin{array}{l}\text { делающцая } \\
\text { delajuščaja }\end{array}$ & $\begin{array}{c}\text { делаюицие } \\
\text { delajuščie }\end{array}$ \\
\hline Gen & \multicolumn{3}{|c|}{$\begin{array}{l}\text { делаюшего } \\
\text { delajuščego }\end{array}$} & $\begin{array}{l}\text { делающей } \\
\text { delajuščej }\end{array}$ & $\begin{array}{l}\text { делаюших } \\
\text { delajuščih }\end{array}$ \\
\hline Dat & \multicolumn{3}{|c|}{$\begin{array}{l}\text { делаюшему } \\
\text { delajušс̌етu }\end{array}$} & $\begin{array}{l}\text { делающей } \\
\text { delajušс̌еj }\end{array}$ & $\begin{array}{l}\text { делаюшимм } \\
\text { delajuščim }\end{array}$ \\
\hline$A c C$ & $\begin{array}{l}\text { делаюшего } \\
\text { delajuščego }\end{array}$ & $\begin{array}{c}\text { делаюиций } \\
\text { delajuščij }\end{array}$ & $\begin{array}{l}\text { делаюшее } \\
\text { delajuščeе }\end{array}$ & $\begin{array}{l}\text { делаюицую } \\
\text { delajиšс̌ији }\end{array}$ & $\begin{array}{l}\text { делающиче } \\
\text { delajuščie }\end{array}$ \\
\hline LoC & \multicolumn{3}{|c|}{$\begin{array}{l}\text { делающемм } \\
\text { delajušс̌еm }\end{array}$} & $\begin{array}{r}\text { делающей } \\
\text { delajuščej }\end{array}$ & $\begin{array}{c}\text { делающихх } \\
\text { delajuščih }\end{array}$ \\
\hline Ins & \multicolumn{3}{|c|}{$\begin{array}{l}\text { делающиим } \\
\text { delajuščim }\end{array}$} & $\begin{array}{l}\text { делающей, делающуею } \\
\text { delajuščej, delajušс̌еји }\end{array}$ & $\begin{array}{c}\text { делающимми } \\
\text { delajuščimi }\end{array}$ \\
\hline
\end{tabular}

Table 57. [ru] ADJ | Aspect=Imp | VerbForm=Part | Voice=Act | Tense=Pres. The adjective Әелающий (delajuščij) means "doing" and is derived from the imperfective verb делать (delat') "to do". The corresponding past adjective is сделавиий (sdelavšij),

it is derived from the perfective verb сделать (sdelat') and uses the same suffixes.

\begin{tabular}{|c|c|c|c|c|c|c|c|c|c|}
\hline $\mathrm{Nu}$ & \multicolumn{4}{|c|}{ Sing } & \multicolumn{2}{|c|}{ Dual } & \multicolumn{3}{|c|}{ Plur } \\
\hline $\mathrm{Ge}$ & \multicolumn{2}{|c|}{ Masc } & Neut & Fem & Masc & Fem, Neut & Masc & Fem & Neut \\
\hline$A n$ & Anim & Inan & & & & & & & \\
\hline Nom & \multicolumn{2}{|c|}{ delajoč } & delajoče & delajoča & delajoča & delajoči & delajoči & delajoče & delajoča \\
\hline Gen & \multicolumn{3}{|c|}{ delajočega } & delajoče & \multicolumn{5}{|c|}{ delajočih } \\
\hline Dat & \multicolumn{3}{|c|}{ delajočemu } & delajoči & \multicolumn{2}{|c|}{ delajočima } & \multicolumn{3}{|c|}{ delajočim } \\
\hline Acc & delajočega & delajoč & delajoče & delajočo & delajoča & delajoči & dela & ijoče & delajoča \\
\hline Loc & \multicolumn{3}{|c|}{ delajočem } & delajoči & \multicolumn{5}{|c|}{ delajočih } \\
\hline Ins & \multicolumn{3}{|c|}{ delajočim } & delajočo & \multicolumn{2}{|c|}{ delajočima } & \multicolumn{3}{|c|}{ delajočimi } \\
\hline
\end{tabular}

Table 58. [sl] ADJ | Aspect=Imp | VerbForm=Part | Voice=Act | Tense=Pres. The adjective delajoč / delajoči means "doing" and is derived from the imperfective verb delati "to do". 


\begin{tabular}{|c|c|c|c|c|c|c|c|}
\hline Number & \multicolumn{4}{|c|}{ Sing } & \multicolumn{3}{|c|}{ Plur } \\
\hline Gender & \multicolumn{2}{|c|}{ Masc } & Neut & Fem & Masc & Fem & Neut \\
\hline Animacy & Anim & Inan & & & & & \\
\hline Nom & \multicolumn{2}{|c|}{ delajući } & delajuće & delajuća & delajući & delajuće & delajuća \\
\hline Gen & \multicolumn{3}{|c|}{ delajućeg } & delajuće & \multicolumn{3}{|c|}{ delajućih } \\
\hline Dat & \multicolumn{3}{|c|}{ delajućem } & delajućoj & \multicolumn{3}{|c|}{ delajućim } \\
\hline$A c c$ & delajućeg & delajući & delajuće & delajuс́u & \multicolumn{2}{|c|}{ delajuće } & delajuća \\
\hline Voc & \multicolumn{2}{|c|}{ delajući } & delajuće & delajuća & delajući & delajuće & delajuća \\
\hline LoC & \multicolumn{3}{|c|}{ delajućem } & delajućoj & \multicolumn{3}{|c|}{ delajućim } \\
\hline Ins & \multicolumn{3}{|c|}{ delajućim } & delajućom & \multicolumn{3}{|c|}{ delajućim } \\
\hline
\end{tabular}

Table 59. [hr] ADJ | Aspect=Imp | VerbForm=Part | Voice=Act | Tense=Pres. The adjective delajući means "doing" and is derived from the imperfective verb delati "to do". The corresponding past adjective is dodelavši, it is derived from the perfective verb dodelati and uses the same suffixes.

\begin{tabular}{|c|c|c|c|c|}
\hline Number & \multicolumn{3}{|c|}{ Sing } & Plur \\
\hline Gender & Masc & Fem & Neut & \\
\hline Ind & $\begin{array}{l}\text { правеш } \\
\text { pravešt }\end{array}$ & $\begin{array}{l}\text { правешца } \\
\text { pravešta }\end{array}$ & $\begin{array}{l}\text { правешуо } \\
\text { pravešto }\end{array}$ & $\begin{array}{l}\text { правешии } \\
\text { pravešti }\end{array}$ \\
\hline Def & $\begin{array}{c}\text { правешиияm } \\
\text { praveštijat }\end{array}$ & $\begin{array}{c}\text { nравешуата } \\
\text { praveštata }\end{array}$ & $\begin{array}{l}\text { правешзото } \\
\text { praveštoto }\end{array}$ & $\begin{array}{c}\text { правешиите } \\
\text { praveštite }\end{array}$ \\
\hline
\end{tabular}

Table 60. [bg] npaвem (pravešt) "doing” ADJ | Aspect=Imp | VerbForm=Part | Voice=Act | Tense=Pres. The rows correspond to different values of Definite.

Bulgarian adjectives do not inflect for Case. 


\begin{tabular}{|c|c|c|c|c|c|c|}
\hline Number & \multicolumn{3}{|c|}{ Sing } & \multicolumn{3}{|c|}{ Dual } \\
\hline Gender & Masc & Neut & Fem & Masc & Neut & Fem \\
\hline Nom & \multicolumn{2}{|c|}{$\begin{array}{l}\text { АЂへaнA } \\
\text { dělaję }\end{array}$} & 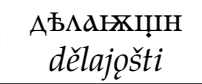 & 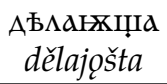 & \multicolumn{2}{|c|}{$\begin{array}{c}\text { Аъ } а \text { ањжцин } \\
\text { dělajošti }\end{array}$} \\
\hline Gen & \multicolumn{2}{|c|}{$\begin{array}{c}\text { АЂиањжџ̣а } \\
\text { dělajošta }\end{array}$} & 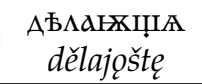 & \multicolumn{3}{|c|}{$\begin{array}{c}\text { АЂぇањжщюу } \\
\text { dělajoštu }\end{array}$} \\
\hline Dat & \multicolumn{2}{|c|}{ 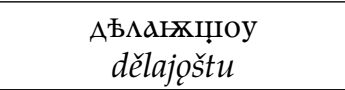 } & $\begin{array}{c}\text { Абиањжщн } \\
\text { dělajošti }\end{array}$ & \multicolumn{2}{|c|}{$\begin{array}{l}\text { Аъцањхщчема } \\
\text { dělajoštema }\end{array}$} & $\begin{array}{l}\text { Аъланжџама } \\
\text { dělajoštama }\end{array}$ \\
\hline$A C C$ & 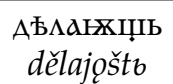 & 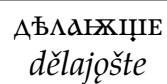 & $\begin{array}{c}\text { АЂ } \\
\text { dělajošto }\end{array}$ & 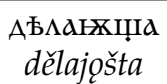 & & 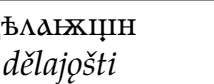 \\
\hline Voc & \multicolumn{2}{|c|}{$\begin{array}{c}\text { АЂরaนA } \\
\text { dělaję }\end{array}$} & $\begin{array}{c}\text { АЂианжџн } \\
\text { dělaješti }\end{array}$ & $\begin{array}{c}\text { АЂианхبа } \\
\text { dělajošta }\end{array}$ & \multicolumn{2}{|c|}{ 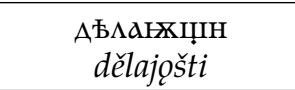 } \\
\hline LoC & \multicolumn{3}{|c|}{$\begin{array}{c}\text { АЂ } \\
\text { dělaješti }\end{array}$} & \multicolumn{3}{|c|}{$\begin{array}{c}\text { АЂ } \\
\text { dělajoštu }\end{array}$} \\
\hline Ins & \multicolumn{2}{|c|}{$\begin{array}{l}\text { АБиаюжцџемь } \\
\text { dělajoštems }\end{array}$} & $\begin{array}{l}\text { АЂ } \\
\text { dělajoštejo }\end{array}$ & \multicolumn{2}{|c|}{$\begin{array}{c}\text { АБиањжџџЕма } \\
\text { dělajoštema }\end{array}$} & $\begin{array}{c}\text { Аълаюжџ̣ама } \\
\text { dělajoštama }\end{array}$ \\
\hline
\end{tabular}

\begin{tabular}{|c|c|c|c|}
\hline Number & \multicolumn{3}{|c|}{ Plur } \\
\hline Gender & Masc & Neut & Fem \\
\hline Nom & 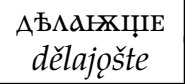 & $\begin{array}{l}\text { Аъмањжџџа } \\
\text { dělajošta }\end{array}$ & $\begin{array}{l}\text { Аъианжџџн } \\
\text { dělajošte }\end{array}$ \\
\hline Gen & \multicolumn{3}{|c|}{$\begin{array}{c}\text { АЂианхبь } \\
\text { dělajoštb }\end{array}$} \\
\hline Dat & \multicolumn{2}{|c|}{$\begin{array}{l}\text { АЂианжџемъ } \\
\text { dělajoštemъ }\end{array}$} & $\begin{array}{l}\text { Аъмањжџџамъ } \\
\text { dělajoštamъ }\end{array}$ \\
\hline Acc & 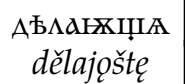 & 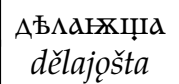 & $\begin{array}{c}\text { АЂианжџџি } \\
\text { dělajoštę }\end{array}$ \\
\hline Voc & 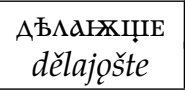 & 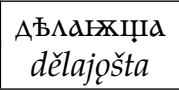 & $\begin{array}{l}\text { АБиањкب̣ی } \\
\text { dělajoštę }\end{array}$ \\
\hline LoC & \multicolumn{2}{|c|}{$\begin{array}{l}\text { АЂцањжџ̣нхъ } \\
\text { dělajoštichъ }\end{array}$} & $\begin{array}{l}\text { АЂ ацжищахъ } \\
\text { dělaještachヶ }\end{array}$ \\
\hline Ins & \multicolumn{2}{|c|}{$\begin{array}{c}\text { Аъцанхب̣н } \\
\text { dělajošti }\end{array}$} & $\begin{array}{c}\text { Аъианжщамн } \\
\text { dělajoštami }\end{array}$ \\
\hline
\end{tabular}

Table 61. [cu] ADJ | Aspect=Imp | VerbForm=Part | Voice=Act | Tense=Pres. The adjective А $\mathrm{b} \Lambda \mathrm{dHA}$ (dělaję) means "doing" and is derived from the imperfective verb АЂцатн (dělati) "to do". The corresponding past adjective is съАъцавъ (sъdělavъ), it is derived from the perfective verb съдъматн (şdělati) and uses similar suffixes: Sing Masc Gen съдъцавъша (sъdělavъša), Sing Fem Nom съдъцавъшн (sъdělavъši) etc. The table shows the short ("strong") forms of the nominal declension. 


\section{Passive Participle}

[cs] příčestí trpné, př́idauné jméno slovesné trpné; [sk] trpné príčastie; [hsb] preteritowy particip; [pl] imiesłów przymiotnikowy bierny; [uk] пасивний дієприкметник; [ru] страдательное причастие; [sl] trpni deležnik; [hr] glagolski pridjev trpni; [bg] минало страдателно причастие. Tables 62-72.

The passive participle is a non-finite verbal form used to construct the periphrastic passive. It is the only form that bears the feature Voice=Pass.

All the other verb forms may take part in passive constructions. Examples [cs]: je nominován "he is (being) nominated"; byl jsem nominován "I was nominated"; byl bych nominován "I would be nominated"; budeš nominován "you will be nominated"; budte nominován "be nominated"; být nominován "to be nominated" etc. It is always the passive participle that makes the construction passive. The auxiliary verb forms do not differ morphologically from the forms used in the active voice, which is the default. Therefore they should either be marked Voice=Act, or the Voice feature should be left empty. We suggest that the explicit annotation of Voice=Act is mandatory for the other participles, so that all types of participles are explicitly distinguished. For the other verbal forms, the feature is optional.

Note that Slavic languages also have the reflexive passive, consisting of a reflexive pronoun and a $3^{\text {rd }}$ person indicative verb ([cs] Prezident se volí každé 4 roky. "The president is elected every 4 years.") Although the analytical construction is passive, the participating verb is morphologically not passive and will not be marked as such. The passive nature of the clause will be visible in the dependency annotation (the subject will be attached as nsubjpass and the reflexive pronoun will be attached using the language-specific relation auxpass: reflex). In [ru] the reflexive pronoun is written as one word with the finite verb: негласно сииталось, ито ему простительно всякое (neglasno sčitalos', čto emu prostitel'no vsjakoe) "it was silently thought that he could be forgiven everything". When it is used to form the reflexive passive, we could in theory mark the whole form as passive; however, we recommend to split the form to two syntactic words (сиитало+сь / sčitalo+s') and make it parallel with the other Slavic languages.

Passive participles may have short and long forms. As explained above (see Section 3 ), this distinction can be interpreted as indefinite vs. definite adjectives in the south Slavic languages. In the north it applies to Czech and Russian, where the short forms are used predicatively, and their Case inflection almost vanished (Czech short participles may form accusative but it is very rare). Since we cannot distinguish the forms by the Definite feature here, we suggest to tag the short forms VERB, even though the remnants of case inflection make this decision slightly inconsistent with the rest. $\underline{12}$ The long forms are also called passive verbal adjectives and we treat them

\footnotetext{
${ }^{12} \mathrm{We}$ also lose the parallelism between short passive participles and short forms of adjectives in Czech (nemocen vs. nemocny "ill"). The short adjectives are used in predicates as well. This is a controversial issue and the guideline we propose may be revised in future.
} 


\begin{tabular}{|c|c|c|c|c|c|c|c|c|}
\hline Number & \multicolumn{4}{|c|}{ Sing } & \multicolumn{4}{|c|}{ Plur } \\
\hline Gender & \multicolumn{2}{|c|}{ Masc } & Neut & Fem & \multicolumn{2}{|c|}{ Masc } & \multirow[t]{2}{*}{ Fem } & \multirow[t]{2}{*}{ Neut } \\
\hline Animacy & Anim & Inan & & & Anim & Inan & & \\
\hline Nom & \multicolumn{2}{|c|}{ dělaný } & dělané & dělaná & dělaní & \multicolumn{2}{|c|}{ dělané } & dělaná \\
\hline Gen & \multicolumn{3}{|c|}{ dělaného } & dělané & \multicolumn{4}{|c|}{ dělaných } \\
\hline Dat & \multicolumn{3}{|c|}{ dělanému } & dělané & \multicolumn{4}{|c|}{ dělaným } \\
\hline$A C C$ & dělaného & dělaný & dělané & dělanou & \multicolumn{3}{|c|}{ dělané } & dělaná \\
\hline Voc & \multicolumn{2}{|c|}{ dělaný } & dělané & dělaná & dělaní & & & dělaná \\
\hline LoC & \multicolumn{3}{|c|}{ dělaném } & dělané & \multicolumn{4}{|c|}{ dělaných } \\
\hline Ins & \multicolumn{3}{|c|}{ dělaným } & dělanou & \multicolumn{4}{|c|}{ dělanými } \\
\hline VERB & děl & & děláno & dělána & děláni & děla & & dělána \\
\hline
\end{tabular}

Table 62. [cs] dělaný / dělán "done” ADJ,VERB | Aspect=Imp | VerbForm=Part | Voice=Pass.

\begin{tabular}{|c|c|c|c|c|c|c|c|}
\hline Number & \multicolumn{4}{|c|}{ Sing } & \multicolumn{3}{|c|}{ Plur } \\
\hline Gender & \multicolumn{2}{|c|}{ Masc } & Neut & Fem & \multicolumn{2}{|c|}{ Masc } & Fem, Neut \\
\hline Animacy & Anim & Inan & & & Anim & Inan & \\
\hline Nom & \multicolumn{2}{|c|}{ robený } & robené & robená & robení & \multicolumn{2}{|c|}{ robené } \\
\hline Gen & \multicolumn{3}{|c|}{ robeného } & robenej & \multicolumn{3}{|c|}{ robených } \\
\hline Dat & \multicolumn{3}{|c|}{ robenému } & robenej & \multicolumn{3}{|c|}{ robeným } \\
\hline$A C C$ & robeného & robený & robené & robenú & robených & & robené \\
\hline Loc & \multicolumn{3}{|c|}{ robenom } & robenej & \multicolumn{3}{|c|}{ robených } \\
\hline Ins & \multicolumn{3}{|c|}{ robeným } & robenou & \multicolumn{3}{|c|}{ robenými } \\
\hline
\end{tabular}

Table 63. [sk] robený "done" ADJ | Aspect=Imp | VerbForm=Part | Voice=Pass.

as adjectives derived from verbs. Their tag should be ADJ and their lemma should be the adjectival form in masculine singular nominative, not the verb infinitive. They can be used as attributive modifiers of noun phrases (with which they agree in gender, number and case).

The long forms of passive participles may also be used in predicates, especially in languages that have only the long forms (e.g. Slovak). However, since they are tagged as adjectives, the dependency layer will analyze them as adjectival predicates with a copula.

In Polish and Ukrainian, the attributive form of singular neuter is different from the predicative one: [uk] писане правило (pysane pravylo) "а written rule" vs. правило 


\begin{tabular}{|c|c|c|c|c|c|c|c|c|c|c|}
\hline $\mathrm{Nu}$ & \multicolumn{4}{|c|}{ Sing } & \multicolumn{3}{|c|}{ Dual } & \multicolumn{3}{|c|}{ Plur } \\
\hline $\mathrm{Ge}$ & \multicolumn{2}{|c|}{ Masc } & Neut & Fem & \multicolumn{2}{|l|}{ Masc } & F. , N. & \multicolumn{2}{|l|}{ Masc } & F., N. \\
\hline An & An. & In. & & & An. & In. & & An. & In. & \\
\hline Nom & \multicolumn{2}{|c|}{ dźéłany } & dźětane & dźětana & dźěłanaj & \multicolumn{2}{|c|}{ dźéłanej } & dźětani & \multicolumn{2}{|c|}{ dźěłane } \\
\hline Gen & \multicolumn{3}{|c|}{ dźětaneho } & dźěłaneje & \multicolumn{3}{|c|}{ dźěłaneju } & \multicolumn{3}{|c|}{ dźéłanych } \\
\hline Dat & \multicolumn{3}{|c|}{ dźěłanemu } & dźěłanej & \multicolumn{3}{|c|}{ dźěłanymaj } & \multicolumn{3}{|c|}{ dźěłanym } \\
\hline AcC & dźěłaneho & dźétany & dźěłane & dźéłanu & dźětaneju & & éłanej & dźětanych & & ěłane \\
\hline LoC & \multicolumn{3}{|c|}{ dźěłanym } & dźěłanej & \multicolumn{3}{|c|}{ dźěłanymaj } & \multicolumn{3}{|c|}{ dźěłanych } \\
\hline Ins & \multicolumn{3}{|c|}{ dźětanym } & dźěłanej & \multicolumn{3}{|c|}{ dźěłanymaj } & \multicolumn{3}{|c|}{ dźětanymi } \\
\hline
\end{tabular}

Table 64. [hsb] dźěłany "done" ADJ | Aspect=Imp | VerbForm=Part | Voice=Pass.

\begin{tabular}{|c|c|c|c|c|c|c|c|}
\hline \multirow{3}{*}{$\begin{array}{c}\text { Number } \\
\text { Gender } \\
\text { Animacy }\end{array}$} & \multicolumn{4}{|c|}{ Sing } & \multicolumn{3}{|c|}{ Plur } \\
\hline & \multicolumn{2}{|c|}{ Masc } & Neut & Fem & \multicolumn{2}{|c|}{ Masc } & Fem, Neut \\
\hline & Anim, Nhum & Inan & & & Anim & Nhum, Inan & \\
\hline \multirow[t]{2}{*}{ Nom } & \multicolumn{2}{|c|}{ robiony } & robione & robiona & robieni & \multicolumn{2}{|c|}{ robione } \\
\hline & & & robiono & & & & \\
\hline Gen & \multicolumn{3}{|c|}{ robionego } & robionej & \multicolumn{3}{|c|}{ robionych } \\
\hline Dat & \multicolumn{3}{|c|}{ robionemu } & robionej & \multicolumn{3}{|c|}{ robionym } \\
\hline AcC & robionego & robiony & robione & robiong & robionych & \multicolumn{2}{|c|}{ robione } \\
\hline Voc & \multicolumn{2}{|c|}{ robiony } & robione & robiona & robieni & robi & one \\
\hline Loc & \multicolumn{3}{|c|}{ robionym } & robionej & \multicolumn{3}{|c|}{ robionych } \\
\hline Ins & \multicolumn{3}{|c|}{ robionym } & robiona & \multicolumn{3}{|c|}{ robionymi } \\
\hline
\end{tabular}

Table 65. [pl] robiony "done" ADJ | Aspect=Imp | VerbForm=Part | Voice=Pass.

писано (pravylo pysano) "a rule is/was written". One might be tempted to tag the predicative forms as VERB instead of ADJ, to make them parallel with the short (predicative) participles in Czech and Russian. Unfortunately, that would mean that two very similar Ukrainian sentences would get different part-of-speech and dependency analyses just because their subjects differ in gender and/or number. Therefore it seems better to classify these forms as adjectives, too.

Slovenian and Serbo-Croatian inflect both short and long adjectives for Case, and the same applies to passive participles (passive verbal adjectives).

Definite adjectives are longer than indefinite also in Bulgarian and Macedonian, although the construction is different from that of [sl] and [hr]. The definite forms are used only attributively, the short forms both as attributes and predicates. As this 


\begin{tabular}{|c|c|c|c|c|c|}
\hline Number & \multicolumn{4}{|c|}{ Sing } & Plur \\
\hline $\mathrm{Ge} / \mathrm{An}$ & M/Anim & M/Inan & Neut & Fem & \\
\hline Nom & \multicolumn{2}{|c|}{$\begin{array}{l}\text { делаемьй } \\
\text { delaетуј }\end{array}$} & $\begin{array}{l}\text { делаемое } \\
\text { delaетое }\end{array}$ & $\begin{array}{l}\text { делаемая } \\
\text { delaетаја }\end{array}$ & $\begin{array}{l}\text { делаемьле } \\
\text { delaemуе }\end{array}$ \\
\hline Gen & \multicolumn{3}{|c|}{$\begin{array}{l}\text { делаемого } \\
\text { delaетово }\end{array}$} & $\begin{array}{l}\text { делаемой } \\
\text { delaетој }\end{array}$ & $\begin{array}{l}\text { делаемьхх } \\
\text { delaemyh }\end{array}$ \\
\hline Dat & \multicolumn{3}{|c|}{$\begin{array}{l}\text { делаемому } \\
\text { delaетоти }\end{array}$} & $\begin{array}{l}\text { делаемой } \\
\text { delaетој }\end{array}$ & $\begin{array}{l}\text { делаемьмм } \\
\text { delaетут }\end{array}$ \\
\hline$A C C$ & $\begin{array}{l}\text { делаемого } \\
\text { delaетоgо }\end{array}$ & $\begin{array}{l}\text { делаемьй } \\
\text { delaетуј }\end{array}$ & $\begin{array}{l}\text { делаемое } \\
\text { delaeтое }\end{array}$ & $\begin{array}{l}\text { делаемую } \\
\text { деlаетији }\end{array}$ & $\begin{array}{c}\text { делаемьхх, делаемьие } \\
\text { delaemyh, delaemуе }\end{array}$ \\
\hline LoC & \multicolumn{3}{|c|}{$\begin{array}{l}\text { делаемом } \\
\text { delaетот }\end{array}$} & $\begin{array}{l}\text { делаемой } \\
\text { delaeтој }\end{array}$ & $\begin{array}{c}\text { делаемьхх } \\
\text { delaemyh }\end{array}$ \\
\hline Ins & \multicolumn{3}{|c|}{$\begin{array}{l}\text { делаемьлм } \\
\text { delaетут }\end{array}$} & $\begin{array}{l}\text { делаемой, делаемою } \\
\text { delaетој, delaетоји }\end{array}$ & $\begin{array}{l}\text { делаемьмми } \\
\text { delaетуті }\end{array}$ \\
\hline VERB & \multicolumn{2}{|c|}{$\begin{array}{l}\text { делаем } \\
\text { delaет }\end{array}$} & $\begin{array}{l}\text { делаемо } \\
\text { delaето }\end{array}$ & $\begin{array}{l}\text { делаема } \\
\text { delaета }\end{array}$ & $\begin{array}{l}\text { делаемь } \\
\text { delaemy }\end{array}$ \\
\hline
\end{tabular}

Table 66. [ru] ADJ, VERB | Aspect=Imp | VerbForm=Part | Voice=Pass | Tense $=$ Pres.

\begin{tabular}{|c|c|c|c|c|c|}
\hline Number & \multicolumn{4}{|c|}{ Sing } & Plur \\
\hline $\mathrm{Ge} / \mathrm{An}$ & M/Anim & M/Inan & Neut & Fem & \\
\hline Nom & \multicolumn{2}{|c|}{$\begin{array}{c}\text { сделанньй } \\
\text { sdelannyj }\end{array}$} & $\begin{array}{l}\text { сделанное } \\
\text { sdelannое }\end{array}$ & $\begin{array}{l}\text { сделанная } \\
\text { sdelanпаја }\end{array}$ & $\begin{array}{l}\text { сделанньие } \\
\text { sdelannye }\end{array}$ \\
\hline Gen & \multicolumn{3}{|c|}{$\begin{array}{l}\text { сделанного } \\
\text { sdelannоgо }\end{array}$} & $\begin{array}{l}\text { сделанной } \\
\text { sdelanпој }\end{array}$ & $\begin{array}{l}\text { сделанньхх } \\
\text { sdelannyh }\end{array}$ \\
\hline Dat & \multicolumn{3}{|c|}{$\begin{array}{l}\text { сделанному } \\
\text { sdelanпоти }\end{array}$} & $\begin{array}{l}\text { сделанной } \\
\text { sdelannој }\end{array}$ & $\begin{array}{c}\text { сделанньим } \\
\text { sdelanпуm }\end{array}$ \\
\hline$A C C$ & $\begin{array}{l}\text { сделанного } \\
\text { sdelannogо }\end{array}$ & $\begin{array}{c}\text { сделанньий } \\
\text { sdelannyj }\end{array}$ & $\begin{array}{l}\text { сделанное } \\
\text { sdelanпое }\end{array}$ & $\begin{array}{l}\text { сделанную } \\
\text { sdelaппији }\end{array}$ & $\begin{array}{l}\text { сделанньх , сделанные } \\
\text { sdelannyh, sdelannye }\end{array}$ \\
\hline LoC & \multicolumn{3}{|c|}{$\begin{array}{l}\text { сделанном } \\
\text { sdelannom }\end{array}$} & $\begin{array}{l}\text { сделанной } \\
\text { sdelannој }\end{array}$ & $\begin{array}{c}\text { сделанньхх } \\
\text { sdelannyh }\end{array}$ \\
\hline Ins & \multicolumn{3}{|c|}{$\begin{array}{l}\text { сделанньим } \\
\text { sdelanпут }\end{array}$} & $\begin{array}{l}\text { сделанной, сделанною } \\
\text { sdelannој, sdelaппоји }\end{array}$ & $\begin{array}{c}\text { сделанньмми } \\
\text { sdelannуmi }\end{array}$ \\
\hline VERB & $\begin{array}{l}\text { cde } \\
\text { sde }\end{array}$ & gan & $\begin{array}{l}\text { сделано } \\
\text { sdelano }\end{array}$ & $\begin{array}{l}\text { сделана } \\
\text { sdelana }\end{array}$ & $\begin{array}{c}\text { сделаньи } \\
\text { sdelany }\end{array}$ \\
\hline
\end{tabular}

Table 67. [ru] сделанный / сделан (sdelannyj / sdelan) “done” ADJ,VERB | Aspect=Perf | VerbForm=Part | Voice=Pass | Tense=Past. 


\begin{tabular}{|c|c|c|c|c|c|c|}
\hline \multirow{3}{*}{$\begin{array}{c}\text { Number } \\
\text { Gender } \\
\text { Animacy }\end{array}$} & \multicolumn{4}{|c|}{ Sing } & \multicolumn{2}{|c|}{ Plur } \\
\hline & \multicolumn{2}{|c|}{ Masc } & Neut & \multirow[t]{2}{*}{ Fem } & & \\
\hline & Anim & Inan & & & Anim & Inan \\
\hline \multirow[t]{2}{*}{ Nom } & \multicolumn{2}{|c|}{$\begin{array}{c}\text { зроблениц } \\
\text { zroblenyj }\end{array}$} & $\begin{array}{l}\text { зроблене } \\
\text { zroblene }\end{array}$ & $\begin{array}{l}\text { зроблена } \\
\text { zroblena }\end{array}$ & \multicolumn{2}{|c|}{$\begin{array}{l}\text { зроблені } \\
\text { zrobleni }\end{array}$} \\
\hline & & & $\begin{array}{l}\text { зроблено } \\
\text { zrobleno }\end{array}$ & & & \\
\hline Gen & \multicolumn{3}{|c|}{$\begin{array}{l}\text { зробленого } \\
\text { zroblenoho }\end{array}$} & $\begin{array}{l}\text { зробленої } \\
\text { zroblenö̈ }\end{array}$ & \multicolumn{2}{|c|}{$\begin{array}{l}\text { зроблених } \\
\text { zroblenych }\end{array}$} \\
\hline Dat & \multicolumn{3}{|c|}{$\begin{array}{l}\text { зробленому } \\
\text { zroblenоти }\end{array}$} & $\begin{array}{l}\text { зробленій } \\
\text { zroblenij }\end{array}$ & \multicolumn{2}{|c|}{$\begin{array}{l}\text { зробленим } \\
\text { zroblenym }\end{array}$} \\
\hline$A C C$ & $\begin{array}{l}\text { зробленого } \\
\text { zroblenoho }\end{array}$ & $\begin{array}{c}\text { зроблений } \\
\text { zroblenyj }\end{array}$ & $\begin{array}{l}\text { зроблене } \\
\text { zroblene }\end{array}$ & $\begin{array}{l}\text { зроблену } \\
\text { zroblenu }\end{array}$ & $\begin{array}{l}\text { зроблених } \\
\text { zroblenych }\end{array}$ & $\begin{array}{l}\text { зроблені } \\
\text { zrobleni }\end{array}$ \\
\hline LoC & \multicolumn{3}{|c|}{$\begin{array}{l}\text { зробленому } \\
\text { zroblenoти }\end{array}$} & $\begin{array}{l}\text { зробленій } \\
\text { zroblenij }\end{array}$ & \multicolumn{2}{|c|}{$\begin{array}{l}\text { зроблених } \\
\text { zroblenych }\end{array}$} \\
\hline Ins & \multicolumn{3}{|c|}{$\begin{array}{l}\text { зробленим } \\
\text { zroblenуm }\end{array}$} & $\begin{array}{l}\text { зробленою } \\
\text { zrobleпоји }\end{array}$ & \multicolumn{2}{|c|}{$\begin{array}{l}\text { зробленими } \\
\text { zroblenуту }\end{array}$} \\
\hline
\end{tabular}

Table 68. [uk] зроблений (zroblenyj) "done" ADJ | Aspect=Perf | VerbForm=Part | Voice=Pass. The Nom-Ins rows show Case inflections of verbal adjectives.

\begin{tabular}{|c|c|c|c|c|}
\hline Number & \multicolumn{3}{|c|}{ Sing } & Plur \\
\hline Gender & Masc & Fem & Neut & \\
\hline Ind & $\begin{array}{l}\text { правен } \\
\text { praven }\end{array}$ & $\begin{array}{l}\text { правена } \\
\text { рravепа }\end{array}$ & $\begin{array}{l}\text { правено } \\
\text { рravепо }\end{array}$ & $\begin{array}{c}\text { правени } \\
\text { praveni }\end{array}$ \\
\hline Def & $\begin{array}{c}\text { правеният } \\
\text { pravenijat }\end{array}$ & $\begin{array}{c}\text { правената } \\
\text { pravenata }\end{array}$ & $\begin{array}{c}\text { правеното } \\
\text { pravenoto }\end{array}$ & $\begin{array}{l}\text { правените } \\
\text { pravenite }\end{array}$ \\
\hline
\end{tabular}

Table 69. [bg] правен (praven) "done" ADJ | Aspect=Imp | VerbForm=Part | Voice=Pass. The rows correspond to different values of Definite. Bulgarian adjectives do not inflect for Case.

also applies to passive participles, it seems appropriate to classify them (both forms) as ADJ. They do not inflect for Case but neither do adjectives because [bg] and [mk] have lost the case system.

Russian and Old Church Slavonic distinguish present and past passive participles:

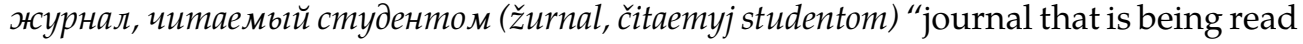
by the student" vs. журнал, прочитанньй студентом (žurnal, pročitannyj studentom) 


\begin{tabular}{|c|c|c|c|c|c|c|c|c|c|}
\hline $\mathrm{Nu}$ & \multicolumn{4}{|c|}{ Sing } & \multicolumn{2}{|c|}{ Dual } & \multicolumn{3}{|c|}{ Plur } \\
\hline $\mathrm{Ge}$ & \multicolumn{2}{|c|}{ Masc } & Neut & Fem & Masc & Fem, Neut & Masc & Fem & Neut \\
\hline$A n$ & Anim & Inan & & & & & & & \\
\hline Nom & \multicolumn{2}{|c|}{ delan } & delano & delana & delana & delani & delani & delane & delana \\
\hline Gen & \multicolumn{3}{|c|}{ delanega } & delane & \multicolumn{5}{|c|}{ delanih } \\
\hline Dat & \multicolumn{3}{|c|}{ delanemu } & delani & \multicolumn{2}{|c|}{ delanima } & \multicolumn{3}{|c|}{ delanim } \\
\hline ACC & delanega & delan & \multicolumn{2}{|c|}{ delano } & delana & delani & \multicolumn{2}{|c|}{ delane } & delana \\
\hline LoC & \multicolumn{3}{|c|}{ delanem } & delani & \multicolumn{5}{|c|}{ delanih } \\
\hline Ins & \multicolumn{3}{|c|}{ delanim } & delano & \multicolumn{2}{|c|}{ delanima } & \multicolumn{3}{|c|}{ delanimi } \\
\hline
\end{tabular}

Table 70. [sl] delan / delani "done" ADJ | Aspect=Imp | VerbForm=Part | Voice=Pass.

\begin{tabular}{|c|c|c|c|c|c|c|c|}
\hline Number & \multicolumn{4}{|c|}{ Sing } & \multicolumn{3}{|c|}{ Plur } \\
\hline Gender & \multicolumn{2}{|c|}{ Masc } & Neut & Fem & Masc & Fem & Neut \\
\hline Animacy & Anim & Inan & & & & & \\
\hline Nom & \multicolumn{2}{|c|}{ delan } & delano & delana & delani & delane & delana \\
\hline Gen & \multicolumn{3}{|c|}{ delanog } & delane & \multicolumn{3}{|c|}{ delanih } \\
\hline Dat & \multicolumn{3}{|c|}{ delanom } & delanoj & \multicolumn{3}{|c|}{ delanim } \\
\hline AcC & delanog & delan & delano & delanu & \multicolumn{2}{|c|}{ delane } & delana \\
\hline Voc & \multicolumn{2}{|c|}{ delan } & delano & delana & delani & delane & delana \\
\hline Loc & \multicolumn{3}{|c|}{ delanom } & delanoj & \multicolumn{3}{|c|}{ delanim } \\
\hline Ins & \multicolumn{3}{|c|}{ delanim } & delanom & \multicolumn{3}{|c|}{ delanim } \\
\hline
\end{tabular}

Table 71. [hr] delan / delani "done" ADJ | Aspect=Imp | VerbForm=Part | Voice $=$ Pass.

"journal that has been read by the student". The distinction will be annotated using the Tense feature. Note that other languages will have the Tense feature empty. Both the above examples will use the same (the only) passive participle in Czech, they will differ only by the prefix because the second verb is perfective: časopis (pře)čtený studentem "journal read by the student".

Passive participles are normally formed for transitive verbs, although verbs that subcategorize for a non-accusative object may also have a passive participle (neuter singular only). 


\begin{tabular}{|c|c|c|c|c|c|c|}
\hline Number & \multicolumn{3}{|c|}{ Sing } & \multicolumn{3}{|c|}{ Dual } \\
\hline Gender & Masc & Neut & Fem & Masc & Neut & Fem \\
\hline Nom & $\begin{array}{l}\text { АБムаЕмъ } \\
\text { dělajem }\end{array}$ & 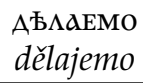 & $\begin{array}{l}\text { АБムаЕма } \\
\text { dělajema }\end{array}$ & $\begin{array}{l}\text { АЂ } \\
\text { dělajema }\end{array}$ & \multicolumn{2}{|c|}{$\begin{array}{l}\text { АБиаЕмЂ } \\
\text { dělajemě }\end{array}$} \\
\hline Gen & \multicolumn{2}{|c|}{$\begin{array}{l}\text { Аъ } \Lambda \text { аЕма } \\
\text { dělajema }\end{array}$} & $\begin{array}{l}\text { АЂへаЕМЫ } \\
\text { dělajemy }\end{array}$ & \multicolumn{3}{|c|}{$\begin{array}{l}\text { АЂлавмоу } \\
\text { dělajemu }\end{array}$} \\
\hline Dat & \multicolumn{2}{|c|}{$\begin{array}{l}\text { АЂ๐аЕмоу } \\
\text { dělajemu }\end{array}$} & $\begin{array}{l}\text { АЂ АаЕМЂ } \\
\text { dělajemě }\end{array}$ & \multicolumn{2}{|c|}{$\begin{array}{l}\text { АЂムаЕмома } \\
\text { dělajemoma }\end{array}$} & $\begin{array}{l}\text { АБиаЕмама } \\
\text { dělajemama }\end{array}$ \\
\hline$A c C$ & 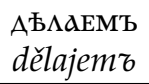 & 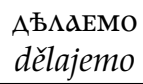 & $\begin{array}{l}\text { АБиавмX } \\
\text { dělajemo }\end{array}$ & 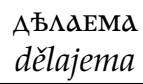 & & $\begin{array}{l}\text { ŠLAEMЂ } \\
\text { Llajemě }\end{array}$ \\
\hline Voc & $\begin{array}{l}\text { АЂیаЕмъ } \\
\text { dělajemъ }\end{array}$ & \multicolumn{2}{|c|}{$\begin{array}{l}\text { АЂ๐аЕмо } \\
\text { dělajemo }\end{array}$} & $\begin{array}{l}\text { АЂ๐аЕма } \\
\text { dělajema }\end{array}$ & \multicolumn{2}{|c|}{$\begin{array}{l}\text { АЂлаЕмњ } \\
\text { dělajemě }\end{array}$} \\
\hline LoC & \multicolumn{3}{|c|}{$\begin{array}{l}\text { АБムаЕМЂ } \\
\text { dělajemé }\end{array}$} & \multicolumn{3}{|c|}{$\begin{array}{l}\text { АБиавмоу } \\
\text { dělajemu }\end{array}$} \\
\hline Ins & \multicolumn{2}{|c|}{$\begin{array}{l}\text { АБムаЕмомь } \\
\text { dělajemomь }\end{array}$} & $\begin{array}{l}\text { АБцаЕмонк } \\
\text { dělajemojo }\end{array}$ & \multicolumn{2}{|c|}{$\begin{array}{l}\text { АЂ АаЕмома } \\
\text { dělajemoma }\end{array}$} & $\begin{array}{l}\text { АЂ๐аЕмама } \\
\text { dělajemama }\end{array}$ \\
\hline
\end{tabular}

\begin{tabular}{|c|c|c|c|}
\hline Number & \multicolumn{3}{|c|}{ Plur } \\
\hline Gender & Masc & Neut & Fem \\
\hline Nom & $\begin{array}{l}\text { АБムаЕмн } \\
\text { dělajemi }\end{array}$ & $\begin{array}{l}\text { АЂ๐аЕма } \\
\text { dělajema }\end{array}$ & $\begin{array}{l}\text { АЂцаЕмы } \\
\text { dělajemy }\end{array}$ \\
\hline Gen & \multicolumn{3}{|c|}{$\begin{array}{l}\text { АБムаЕмъ } \\
\text { dělajemъ }\end{array}$} \\
\hline Dat & \multicolumn{2}{|c|}{$\begin{array}{l}\text { АЂлаЕмомъ } \\
\text { dělajemomъ }\end{array}$} & 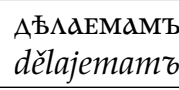 \\
\hline$A C C$ & $\begin{array}{l}\text { АЂцавмы } \\
\text { dělajemy }\end{array}$ & 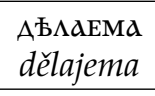 & $\begin{array}{l}\text { АЂцаЕмы } \\
\text { dělajemy }\end{array}$ \\
\hline Voc & $\begin{array}{l}\text { AЂরаЕмн } \\
\text { dělajemi }\end{array}$ & $\begin{array}{l}\text { АБиаЕма } \\
\text { dělajema }\end{array}$ & $\begin{array}{l}\text { АЂлаЕмЫ } \\
\text { dělajemy }\end{array}$ \\
\hline LoC & \multicolumn{2}{|c|}{$\begin{array}{l}\text { АЂ АаЕмъХъ } \\
\text { dělajoštichъ }\end{array}$} & $\begin{array}{l}\text { АЂ } \\
\text { dělajoštach }\end{array}$ \\
\hline Ins & \multicolumn{2}{|c|}{$\begin{array}{l}\text { АБиавмы } \\
\text { dělajemy }\end{array}$} & $\begin{array}{l}\text { АЂیаЕмамн } \\
\text { dělajemami }\end{array}$ \\
\hline
\end{tabular}

Table 72. [cu] ADJ | Aspect=Imp | VerbForm=Part | Voice=Pass | Tense=Pres. The adjective А

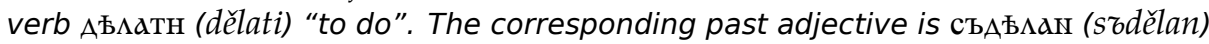
"done", it is derived from the perfective verb съАъцатн (sødělati) and uses similar suffixes: Sing Fem Nom съдъцана (sødělana), Sing Neut Nom съдъцано (şdělano) etc. The table shows the short ("strong") forms of the nominal declension. 


\begin{tabular}{|c|c|c|c|c|c|c|c|c|}
\hline Example & Gloss & Languages & $\mathrm{L}$ & Tag & VerbFo & Voic & Tense & Defin \\
\hline budoucí & what will be & all? & 1 & ADJ & (Part) & & (Fut) & \\
\hline delajoč & who is doing & $\mathrm{sl}, \mathrm{bg}, \mathrm{cu}$ & $\mathrm{s}$ & $A D J$ & Part & Act & Pres & Ind \\
\hline dělající & who is doing & all & 1 & ADJ & Part & Act & Pres & (Def) \\
\hline съАЂ Аавъ & who has done & $\mathrm{cu}$ & $\mathrm{s}$ & ADJ & Part & Act & Past & Ind \\
\hline udělavší & who has done & $\begin{array}{l}\text { cs, sk, hsb, pl } \\
\text { uk, ru, hr }\end{array}$ & 1 & ADJ & Part & Act & Past & (Def) \\
\hline dělal & did / (has) done & all & $\mathrm{s}$ & $\begin{array}{l}\text { VERB } \\
\text { AUX }\end{array}$ & Part & Act & Past & \\
\hline правел & was doing & bg & $\mathrm{s}$ & VERB & Part & Act & Imp & \\
\hline minulý & what has passed & all? & 1 & ADJ & (Part) & & (Past) & \\
\hline dělán & (is (being)) done & $\mathrm{CS}$ & $\mathrm{s}$ & VERB & Part & Pass & & \\
\hline delan & ((who) is) done & $\mathrm{sl}, \mathrm{hr}, \mathrm{bg}$ & $\mathrm{s}$ & ADJ & Part & Pass & & Ind \\
\hline dělaný & who is/was done & $\begin{array}{l}\text { cs, sk, hsb, pl, } \\
\text { uk, sl, hr, bg }\end{array}$ & 1 & $A D J$ & Part & Pass & & (Def) \\
\hline делаем & (is being) done & $\mathrm{ru}$ & $\mathrm{s}$ & VERB & Part & Pass & Pres & \\
\hline АЂムवЕMЬ & (is being) done & $\mathrm{cu}$ & $\mathrm{s}$ & ADJ & Part & Pass & Pres & Ind \\
\hline делаемьй & who is being done & $\mathrm{ru}, \mathrm{cu}$ & 1 & ADJ & Part & Pass & Pres & (Def) \\
\hline сделан & (has been, is) done & $\mathrm{ru}$ & $\mathrm{s}$ & VERB & Part & Pass & Past & \\
\hline съАЂ $\Lambda$ वस & (who is) done & $\mathrm{cu}$ & $\mathrm{s}$ & ADJ & Part & Pass & Past & Ind \\
\hline сделанный & who has been done & $\mathrm{ru}, \mathrm{cu}$ & 1 & ADJ & Part & Pass & Past & (Def) \\
\hline
\end{tabular}

Table 73. Participles. The "L" column denotes short vs. long forms. The Def feature only applies in languages where the Ind counterpart exists.

\section{Participle Summary}

Participles are words that share properties of verbs and adjectives. Just like adjectives, they have short and long forms. Historically, the long forms emerged as a fusion of the short form and a pronoun. North Slavic languages either do not have the short form or they do not mark the Case on it. Short and long forms are distinguished by the POS tag (VERB/ADJ). South Slavic languages use the short form and inflect it for Case (except for [bg] and [mk], which have lost cases). The long form is definite. Both forms are ADJ; short vs. long is distinguished by Definite=Ind/Def. The l-participle is special. Its short form is VERB even in the south Slavic languages (the Definite and Case features of the short form are empty). Table 73 gives a summary of the proposed annotation of participles. Adverbial participles are not covered here because we tag them as transgressives (VerbForm=Trans, see Section 12). [cu] does not have transgres- 


\begin{tabular}{|c|c|c|}
\hline Number & Sing & Plur \\
\hline Nom & dělání & dělání \\
\hline Gen & dělání & dělání \\
\hline Dat & dělání & děláním \\
\hline Acc & dělání & dělání \\
\hline Voc & dělání & dělání \\
\hline Loc & dělání & děláních \\
\hline Ins & děláním & děláními \\
\hline
\end{tabular}

Table 74. [cs] dělání "doing" NOUN | Aspect=Imp. The rows correspond to different values of Case.

\begin{tabular}{|c|c|c|}
\hline Number & Sing & Plur \\
\hline Nom & robenie & robenia \\
\hline Gen & robenia & robení \\
\hline Dat & robeniu & robeniam \\
\hline Acc & robenie & robenia \\
\hline Loc & robení & robeniach \\
\hline Ins & robenim & robeniami \\
\hline
\end{tabular}

Table 75. [sk] robenie "doing" NOUN | Aspect=Imp. The rows correspond to different values of Case.

sives but the nominative forms of its active participles correspond to transgressives and can be used as adverbial modifiers.

\section{Verbal Noun}

[cs] podstatné jméno slovesné; [sk] slovesné podstatné meno; [hsb] werbalny substantiw; [pl] rzeczownik odczasownikowy; [uk] віддієслівний іменник; [ru] отглагольное существительное; [sl] glagolsko ime; [hr] radna (glagolska) imenica; [bg] отглаголно съшествително име. Tables 74-83.

Verbal noun is an abstract noun productively derived from a verb, denoting the action of the verb. It inflects for Case and Number, although it is only rarely seen in plural. Its gender is always Neut. We tag it NOUN and use its singular nominative form as the lemma (not the infinitive of the base verb).

The UD guidelines v1 suggest that VerbForm=Ger can be used to distinguish verbal nouns from other nouns. This works in English where the corresponding form is 


\begin{tabular}{|c|c|c|c|}
\hline Number & Sing & Dual & Plur \\
\hline Nom & dźéłanje & dźéłani & dźéłanja \\
\hline Gen & dźéłanja & \multicolumn{2}{|c|}{ dźéłanjow } \\
\hline Dat & dźéłanju & dźéłanjomaj & dźéłanjam \\
\hline Acc & dźéłanje & dźéłani & dźéłanja \\
\hline Loc & dźéłanju & dźéłanjomaj & dźěłanjach \\
\hline Ins & dźéłanjom & dźěłanjomaj & dźéłanjemi \\
\hline
\end{tabular}

Table 76. [hsb] dźěłanje "doing" NOUN | Aspect=Imp. The rows correspond to different values of Case.

\begin{tabular}{|c|c|c|}
\hline Number & Sing & Plur \\
\hline Nom & robienie & robienia \\
\hline Gen & robienia & robień \\
\hline Dat & robieniu & robieniom \\
\hline Acc & robienie & robienia \\
\hline Voc & robienie & robienia \\
\hline Loc & robieniu & robieniach \\
\hline Ins & robieniem & robieniami \\
\hline
\end{tabular}

Table 77. [pl] robienie "doing" NOUN | Aspect=Imp. The rows correspond to different values of Case.

termed gerund. Unfortunately, this feature might cause confusion in Slavic linguistics where some authors use the term gerund for adverbial participles (cf. Section 12). Hence we advise against using it with Slavic verbal nouns. Nevertheless, the verbal nouns may mark the Aspect of their base verb.

Verbal nouns use suffixes similar to passive participles. Unlike passive participles, they can be derived from intransitive verbs as well.

\section{Negation}

Slavic verbs are negated by a local variant of the morpheme ne, which is either a bound morpheme (prefix), or a separate word (particle). If it is a prefix, we do not cut it off during tokenization.

A standalone negating word is tagged PART and it has the feature Negative=Neg. On the dependency level, it is attached to the negated verb using the neg relation. 


\begin{tabular}{|c|c|c|}
\hline Number & Sing & Plur \\
\hline Nom & $\begin{array}{l}\text { роблення } \\
\text { roblenпја }\end{array}$ & $\begin{array}{l}\text { роблення } \\
\text { roblennja }\end{array}$ \\
\hline Gen & $\begin{array}{l}\text { роблення } \\
\text { roblenпја }\end{array}$ & $\begin{array}{l}\text { роблень } \\
\text { roblen' }\end{array}$ \\
\hline Dat & $\begin{array}{l}\text { робленню } \\
\text { roblenпји }\end{array}$ & $\begin{array}{l}\text { робленням } \\
\text { roblennјат }\end{array}$ \\
\hline$A c C$ & $\begin{array}{l}\text { роблення } \\
\text { roblennja }\end{array}$ & $\begin{array}{l}\text { роблення } \\
\text { roblennja }\end{array}$ \\
\hline LoC & $\begin{array}{l}\text { робленні, робленню } \\
\text { roblenni, roblenпји }\end{array}$ & $\begin{array}{l}\text { робленнях } \\
\text { roblennjach }\end{array}$ \\
\hline Ins & $\begin{array}{l}\text { робленням } \\
\text { roblennjam }\end{array}$ & $\begin{array}{l}\text { робленнями } \\
\text { roblennјату }\end{array}$ \\
\hline
\end{tabular}

Table 78. [uk] роблення (roblennja) "doing" NOUN | Aspect=Imp. The rows correspond to different values of Case.

In the case of the negative prefix, the verb itself bears the Negative=Neg feature. This type of prefixing is considered inflectional rather than derivational, that is, the lemma is still the affirmative (unprefixed) infinitive. If the language negates verbs by prefixing, all affirmative forms of these verbs should be annotated Negative=Pos.

In periphrastic constructions it is normal that only one participating word is negated, but various languages may have different rules on what participant it should be. Cf. [cs] V̌̌era jsem nešel domů. "I did not go home yesterday." (negated participle) and [hr] Jučer nisam išao kući. (negated auxiliary).

Verbal adjectives (long forms of participles) and verbal nouns are negated in a similar fashion.

Czech is an example of a language where all verbs are negated using the prefix ne-. Russian is an example of the opposite: all finite forms and the 1-participles are negated using the particle $\mathrm{He}$ (ne). With the other participles it becomes a prefix though: несовершенный (nеsоveršennyj) "imperfect". Yet different is Croatian where the negative particle is the default, except for the verbs biti, htjeti and imati that take the negative morpheme as a prefix.

\section{Current Data}

UD version 1.2, released in November 2015, contains data from 6 Slavic languages: Czech, Polish, Slovenian, Croatian, Bulgarian and Old Church Slavonic. Most of these datasets distinguish AUX from VERB (except for [cu], which uses only the VERB tag) and most of them have a non-empty value of VerbForm for all verbs (auxiliary or not). Here 


\begin{tabular}{|c|c|c|}
\hline Number & Sing & Plur \\
\hline Nom & $\begin{array}{l}\text { делание, деланье } \\
\text { delanie, delan'e }\end{array}$ & $\begin{array}{l}\text { делания, деланья } \\
\text { delanija, delan'ja }\end{array}$ \\
\hline Gen & $\begin{array}{l}\text { делания, деланья } \\
\text { delanija, delan'ja }\end{array}$ & $\begin{array}{c}\text { деланий } \\
\text { delanij }\end{array}$ \\
\hline Dat & $\begin{array}{l}\text { деланию, деланью } \\
\text { delaniju, delan'ји }\end{array}$ & $\begin{array}{l}\text { деланиям, деланьям } \\
\text { delanijam, delan'jam }\end{array}$ \\
\hline$A C C$ & $\begin{array}{c}\text { делание, деланье } \\
\text { delanie, delan'e }\end{array}$ & $\begin{array}{c}\text { делания, деланья } \\
\text { delanija, delan'ja }\end{array}$ \\
\hline LoC & $\begin{array}{c}\text { делании, деланье, деланьи } \\
\text { delanii, delan'e, delan'i }\end{array}$ & $\begin{array}{c}\text { деланиях, деланьях } \\
\text { delanijah, delan'jah }\end{array}$ \\
\hline Ins & $\begin{array}{c}\text { деланием, деланьем } \\
\text { delaniem, delan'em }\end{array}$ & $\begin{array}{c}\text { деланиями, деланьями } \\
\text { delanijami, delan'jami }\end{array}$ \\
\hline
\end{tabular}

Table 79. [ru] делание (delanie) "doing" Noun | Aspect=Imp. The rows correspond to different values of Case.

the exceptions are [hr] (finite verbs are not marked), [pl] (predicative nonverbs such as to "it (is)" are tagged VERB) and [bg] (empty VerbForms are probably annotation errors). [cu] uses the subjunctive mood (Mood=Sub) instead of Mood=Cnd for the conditional auxiliaries.

All but [bg] have occurrences of VerbForm=Inf, [cu] and [sl] also have VerbForm=Sup.

All languages except [pl] tag verbal nouns as regular NOUN, without setting the VerbForm. Polish tags them VERB with VerbForm=Ger.

VerbForm=Trans is used in [cs], [pl] and [sl]; In Czech and Polish their main part of speech is VERB (or AUX) while in Slovenian it is ADV. Croatian data ignores the Trans value and annotates transgressives as ADV plus VerbForm=Part. Bulgarian tags them as regular adverbs, without any distinctive feature.

By far the largest proportion of inconsistency is caused by participles.

[cs]: The l-participles are tagged VERB/AUX VerbForm=Part | Tense=Past | Voice= Act. Short forms of passive participles are tagged VERB VerbForm=Part | Voice=Pass (empty Tense). Long forms are tagged as regular adjectives (empty VerbForm). Active participles related to transgressives are tagged ADJ VerbForm=Part | Voice=Act and distinguished by tense and aspect: either Aspect=Imp | Tense=Pres or Aspect=Perf | Tense=Past.

[pl]: All participles are tagged VERB. Present active (progressive) participles are marked Voice=Act | Tense=Pres, while the passive participles have Voice=Pass and empty Tense. The 1-participles are marked as finite forms (VerbForm=Fin instead of Part!) with Tense=Past and empty Voice. 


\begin{tabular}{|c|c|c|c|}
\hline Number & Sing & Dual & Plur \\
\hline Nom & delanje & delanji & delanja \\
\hline Gen & delanja & \multicolumn{2}{|c|}{ delanj } \\
\hline Dat & delanju & delanjema & delanjem \\
\hline AcC & delanje & delanji & delanja \\
\hline Loc & delanju & \multicolumn{2}{|c|}{ delanjih } \\
\hline Ins & delanjem & delanjema & delanji \\
\hline
\end{tabular}

Table 80. [sl] delanje "doing" NOUN | Aspect=Imp. The rows correspond to different values of Case.

\begin{tabular}{|c|c|c|}
\hline Number & Sing & Plur \\
\hline Nom & delanje & delanja \\
\hline Gen & delanja & delanja \\
\hline Dat & delanju & delanjima \\
\hline Acc & delanje & delanja \\
\hline Voc & delanje & delanja \\
\hline Loc & delanju & delanjima \\
\hline Ins & delanjem & delanjima \\
\hline
\end{tabular}

Table 81. [hr] delanje "doing" NOUN | Aspect=Imp. The rows correspond to different values of Case.

[sl]: The predicatively used 1-participles are tagged VERB/AUX VerbForm=Part, with empty Voice and Tense. Participles tagged as adjectives (ADJ VerbForm=Part) are mostly passive participles, albeit their Voice feature is empty, too. However, some of them are adjectives derived from the 1-participles (minuli, ostali, odrasle) and rarely also the present active participle (boleče).

[hr]: The l-participles are tagged VERB/AUX VerbForm=Part and they are the only active participles marked. Passive participles are tagged ADJ VerbForm=Part. The Tense and Voice features are always empty.

[bg]: Only the l-participles of the verb to be are tagged VERB/AUX VerbForm=Part. Predicatively used 1-participles of other verbs appear as finite verbs (VerbForm=Fin), they are thus indistinguishable from the aorist and imperfect simple past tenses, respectively. For example, both можах and могъл (aorist and perfect 1-participle of could) are annotated Voice=Act | Tense=Past. In parallel, both можеx and можел (simple imperfect and imperfect l-participle of the same verb) are annotated Voice=Act 


\begin{tabular}{|c|c|c|}
\hline Number & Sing & Plur \\
\hline Ind & $\begin{array}{c}\text { nравене } \\
\text { pravene }\end{array}$ & $\begin{array}{c}\text { nравения, правенета } \\
\text { pravenija, pravenеta }\end{array}$ \\
\hline Def & $\begin{array}{c}\text { nравенето } \\
\text { pravenеto }\end{array}$ & $\begin{array}{c}\text { nравенияma, npaвенетата } \\
\text { pravenijata, pravenetata }\end{array}$ \\
\hline
\end{tabular}

Table 82. [bg] правене (pravene) "doing" NOUN | Aspect=Imp. The rows correspond to different values of Definite. Bulgarian nouns do not inflect for Case.

\begin{tabular}{|c|c|c|c|}
\hline Number & Sing & Dual & Plur \\
\hline Nom & $\begin{array}{l}\text { АБムanHe } \\
\text { dělanije }\end{array}$ & $\begin{array}{c}\text { АЂлаNнн } \\
\text { dělanii }\end{array}$ & $\begin{array}{l}\text { Аъианнњ } \\
\text { dělanija }\end{array}$ \\
\hline Gen & $\begin{array}{c}\text { Аъманнњ } \\
\text { dělanija }\end{array}$ & $\begin{array}{l}\text { Аъцанню } \\
\text { dělaniju }\end{array}$ & $\begin{array}{c}\text { Аъманнн } \\
\text { dělanii }\end{array}$ \\
\hline Dat & $\begin{array}{l}\text { АЂぇанню } \\
\text { dělaniju }\end{array}$ & 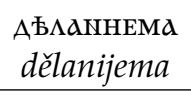 & $\begin{array}{l}\text { АЂ } \\
\text { dělanijemв }\end{array}$ \\
\hline$A C C$ & $\begin{array}{l}\text { АБムаnнe } \\
\text { dělanije }\end{array}$ & $\begin{array}{l}\text { АЂ } \\
\text { dělanii }\end{array}$ & $\begin{array}{l}\text { Аъианнъ } \\
\text { dělanija }\end{array}$ \\
\hline Voc & $\begin{array}{l}\text { АЂরаNHE } \\
\text { dělanije }\end{array}$ & $\begin{array}{c}\text { Аъианнн } \\
\text { dělanii }\end{array}$ & $\begin{array}{c}\text { Аъианнъ } \\
\text { dělanija }\end{array}$ \\
\hline LoC & $\begin{array}{l}\text { АЂへаннн } \\
\text { dělanii }\end{array}$ & $\begin{array}{c}\text { Аъианню } \\
\text { dělaniju }\end{array}$ & $\begin{array}{c}\text { АБиамннхъ } \\
\text { dělaniichъ }\end{array}$ \\
\hline Ins & $\begin{array}{l}\text { АЂ } \\
\text { dělanijems }\end{array}$ & $\begin{array}{c}\text { АЂлаNнема } \\
\text { dělanijema }\end{array}$ & $\begin{array}{c}\text { АЂ๐аNнн } \\
\text { dělanii }\end{array}$ \\
\hline
\end{tabular}

Table 83. [cu] АЂরanhe (dělanije) “doing" NOUN | Aspect=Imp. The rows correspond to different values of Case.

| Tense=Imp. All other participles, including some l-participles, are tagged ADJ Verb Form=Part (they actually can take the definite suffix: миналата, останалите, миналия). Passive participles have empty Tense. Active participles are distinguished by Tense= Pres (imperfective verbs, progressive meaning) and Tense=Past (the l-participles).

[cu]: All participles are tagged VERB VerbForm=Part and no other part-of-speech tag occurs with the VerbForm feature. Except for the 1-participle, which is relatively rare, all participle types can inflect for Case. Active participles are further distinguished by Tense=Pres, Past and in one case even Fut (вжАжцнн). The l-participles have Voice=Act but no Tense; on the other hand, they have currently a special value 
of Aspect=Res, disregarding the lexical aspect of the lemma. Passive participles use the Tense feature to distinguish present and past forms.

\section{Conclusion}

We have presented the various combinations of morphological features of verbs that occur in Slavic languages, and we have proposed their unified and consistent representation within the Universal Dependencies framework. There already exist UD treebanks of six Slavic languages and we have shown that their authors have not always applied the UD annotation style in the same manner. Datasets for other languages are being prepared at the time of this writing, and their authors will have to take similar decisions. Our proposal should contribute to further harmonization of all these datasets: we hope to trigger discussion that will eventually lead to a more precise specification of UD guidelines for Slavic languages.

\section{Acknowledgments}

The author wishes to thank the following people for their valuable comments: Kaja Dobrovoljc, Natalia Kotsyba, Patrice Pognan, Martin Popel, Alexandr Rosen and Zdeněk Žabokrtský. This work has been supported by the Czech Science Foundation (GAČR) grant no. GA15-10472S. It has been using language resources stored and distributed by the LINDAT/CLARIN project of the Ministry of Education, Youth and Sports of the Czech Republic (project LM2015071). 


\section{Bibliography}

Academia. Mluvnice češtiny (2) Tvarosloví. Academia, nakladatelství Československé akademie věd, Praha, Czechoslovakia, 1986.

Breu, Walter. Probleme der Interaktion von Lexik und Aspekt (ILA), volume 412 of Linguistische Arbeiten. Niemeyer, Tübingen, Germany, 2000. ISBN 3-484-30412-X.

Comrie, Bernard and Greville G. Corbett. The Slavonic Languages. Routledge, London, UK, 2001. ISBN 0-415-04755-2.

Erjavec, Tomaž. MULTEXT-East: Morphosyntactic Resources for Central and Eastern European Languages. Language Resources and Evaluation, 46(1):131-142, 2012.

Komárek, Miroslav, Václav Vážný, and František Trávníček. Historická mluvnice česká II. Tvarosloví. Státní pedagogické nakladatelství, Praha, Czechoslovakia, 1967.

Nedjalkov, Vladimir P. and Igor' V. Nedjalkov. On the typological characteristics of converbs. In Help, Toomas, editor, Symposium on language universals, pages 75-79, Tallinn, Soviet Union, 1987.

Nivre, Joakim, Marie-Catherine de Marneffe, Filip Ginter, Yoav Goldberg, Jan Hajič, Christopher Manning, Ryan McDonald, Slav Petrov, Sampo Pyysalo, Natalia Silveira, Reut Tsarfaty, and Daniel Zeman. Universal Dependencies v1: A Multilingual Treebank Collection. In Proceedings of the 10th International Conference on Language Resources and Evaluation (LREC 2016), Portorož, Slovenia, 2016. European Language Resources Association.

Przepiórkowski, Adam and Marcin Woliński. A Flexemic Tagset for Polish. In Proceedings of Morphological Processing of Slavic Languages, EACL 2003, 2003. URL http://nlp. ipipan. waw. pl/ adamp/Papers/2003-eacl-ws12/ws12. pdf.

Zeman, Daniel. Reusable Tagset Conversion Using Tagset Drivers. In Proceedings of the 6th International Conference on Language Resources and Evaluation (LREC 2008), pages 213-218, Marrakech, Morocco, 2008. European Language Resources Association. ISBN 2-9517408-40 .

Zeman, Daniel. Slavic Languages in Universal Dependencies. In Gajdošová, Katarína and Adriána Žáková, editors, Natural Language Processing, Corpus Linguistics, E-learning (proceedings of SLOVKO 2015), pages 151-163, Bratislava, Slovakia, 2015. Slovenská akadémia vied, RAM-Verlag. ISBN 978-3-942303-32-3.

\section{Address for correspondence:}

Daniel Zeman

zeman@ufal.mff.cuni.cz

Ústav formální a aplikované lingvistiky

Matematicko-fyzikální fakulta

Univerzita Karlova v Praze

Malostranské náměstí 25

CZ-11800 Praha, Czechia 